FEDERAL

RESERVE

BANK of

ST. LOUIS

\section{RESEARCH DIVISION} Working Paper Series

\title{
Government Policy in Monetary Economies
}

\author{
Fernando M. Martin
}

Working Paper 2011-026B

https://doi.org/10.20955/wp.2011.026

January 2012

\section{FEDERAL RESERVE BANK OF ST. LOUIS \\ Research Division \\ P.O. Box 442 \\ St. Louis, MO 63166}

The views expressed are those of the individual authors and do not necessarily reflect official positions of the Federal Reserve Bank of St. Louis, the Federal Reserve System, or the Board of Governors.

Federal Reserve Bank of St. Louis Working Papers are preliminary materials circulated to stimulate discussion and critical comment. References in publications to Federal Reserve Bank of St. Louis Working Papers (other than an acknowledgment that the writer has had access to unpublished material) should be cleared with the author or authors. 


\title{
Government Policy in Monetary Economies
}

\author{
Fernando M. Martin* \\ Federal Reserve Bank of St. Louis and Simon Fraser University
}

January 24, 2012

\begin{abstract}
I study how the general and specific details of a micro founded monetary framework affect the determination of policy when the government has limited commitment. The conduct of policy depends on the interaction between the incentive to smooth distortions intertemporally and a time-consistency problem. In equilibrium, fiscal and monetary policies are distortionary, but long-run policy is not afflicted by time-consistency problems. Policy variables in specific applications of the general framework react similarly to variations in fundamentals. Nevertheless, resolving certain environment frictions affect long-run policy significantly. The response of government policy to aggregate shocks is qualitatively similar across the studied model variants. However, there are significant quantitative differences in the response of government policy to productivity shocks, mainly due to the idiosyncratic behavior of the money demand. Environments with no trading frictions display the best fit to post-war U.S. data.
\end{abstract}

Keywords: government policy; limited commitment; Markov-perfect equilibrium; financial intermediation; trading frictions; micro founded models of money.

JEL classification: E13, E52, E62, E63

\footnotetext{
*Email: fernando.m.martin@stls.frb.org. I thank two anonymous referees for helpful comments and suggestions. I also benefited from conversations with Gabriele Camera. I gratefully acknowledge financial support from the SFU/SSHRC Institutional Grants Committee. Preliminary results of this paper were presented at the 2009 Chicago Fed Summer Workshop on Money, Banking, Payment and Finance. The views expressed in this paper do not necessarily reflect official positions of the Federal Reserve Bank of St. Louis, the Federal Reserve System, or the Board of Governors.
} 


\section{Introduction}

Monetary theorists have long stressed the importance of analyzing monetary policy in the context of environments that have an explicit, micro founded role for money (e.g., see Wallace, 1998, 2001 and Williamson and Wright, 2010 for recent expositions). Following the work by Kocherlakota (1998), it is agreed that these environments should feature a double coincidence of wants problem, imperfect record keeping and limited commitment. Beyond this set of minimal frictions, there does not appear to be any guide as to which other details or frictions we should attribute to artificial economies when studying government policy. For example, do we assume competitive markets or bilateral meetings? Do we allow for financial intermediation?

Due to the interaction between fiscal and monetary policies, it seems reasonable to expect that the specific details of a monetary economy may alter our analysis and conclusions regarding the (endogenous) determination of government actions. ${ }^{1}$ However, it is not immediately apparent which results are altered by the idiosyncratic properties of a monetary environment and whether these effects, if present, are quantitatively significant.

In this paper, I analyze how the general and specific details of micro founded monetary economies affect the determination of government policy, both in the long-run and in response to aggregate shocks. To this end, I study policy within the monetary framework proposed by Lagos and Wright (2005), with the addition of a benevolent government that cannot commit to future policy choices and uses money, nominal bonds and distortionary taxes to finance the provision of a valued public good. As shown in Martin (2009, 2011b), limited commitment on the part of the government provides a mechanism that explains the level of debt and, by extension, other policy variables.

I begin the analysis by deriving the theoretical properties of government policy with limited commitment in a general monetary framework, which extends the findings in Martin (2011b). In this class of environments, the classic incentive to smooth distortions intertemporally (as in Barro, 1979 and Lucas and Stokey, 1983) is weighted against a time-consistency problem created by the interaction between debt and monetary policy. How much debt the government inherits affects its monetary policy since inflation reduces the real value of nominal liabilities. In turn, the anticipated response of future monetary policy affects the current demand for money and bonds, and thereby how the government today internalizes policy trade-offs.

Assuming initial net nominal liabilities (money plus bonds) are non-negative, the following results hold in the general framework. ${ }^{2}$ First, the government always chooses to carry-over strictly positive net nominal liabilities. Second, both fiscal and monetary policies are distortionary. In particular, the government never implements the Friedman rule of zero nominal interest rates. Third, despite these properties, long-run policy is not afflicted by time-consistency problems: assuming no aggregate uncertainty, endowing a government at the steady state with a commitment technology would have no effect on policy.

Next, I consider three specific variants of the underlying monetary economy: "competitive markets", assumes all markets are perfectly competitive; "financial intermediation", assumes the existence of a technology that records financial (but not goods) transactions, which allows for the intermediation of fiat money, as in Berentsen et al. (2007); and "trading frictions", assumes decentralized exchange in some markets and introduces an inefficiency due to bargaining

\footnotetext{
${ }^{1}$ The link between fiscal and monetary policy is both theoretically and empirically relevant. Ohanian (1998) provides a thorough historical account for the U.S. economy. Sargent and Wallace (1981) first showed how the effects of monetary policy are affected by a given fiscal policy. Lucas (1986) famously postulated a set of principles for optimal fiscal and monetary policy. See Martin (2009) and Martin (2011b) for further discussion in the context of environments with limited commitment.

${ }^{2}$ See Martin $(2011 b)$ for a characterization of policy when initial net nominal liabilities are negative, in a specific application of the framework studied here.
} 
over the terms of trade. The set of model variants considered here, although not exhaustive, is fairly representative of the type of micro founded monetary economies we would adopt to study the determination of government policy. The three environments only differ in the number of frictions that are present. The case with financial intermediation has only those frictions necessary to make a medium of exchange essential, as enumerated above; the case with competitive markets adds a financial friction which precludes the intermediation of fiat money in some markets; finally, the case with trading frictions features both financial and trading frictions.

I find that the response of long-run policy variables to permanent changes in fundamentals is largely similar across environments, both qualitatively and quantitatively. However, the effects of frictions is quantitatively significant. Specifically, resolving trading frictions implies higher long-run debt and inflation, whereas resolving financial frictions has the opposite effect.

To evaluate the response of government policy to aggregate shocks, I consider two sources of aggregate fluctuations at annual frequencies: shocks to the marginal value of the public good ("expenditure" shocks) and shocks to the productivity of labor. The simulated economies match basic time-series properties of the post-war U.S. economy. The policy response to aggregate shocks is qualitatively similar in the three variants considered. However, there are some significant quantitative differences in the response of debt and inflation to productivity shocks.

To further compare the three environments and assess their relative empirical plausibility, I evaluate their implications along three dimensions: the persistence of policy variables; the relationship between the nominal interest rate and velocity of circulation (i.e., the money demand function); and the relationship between inflation and GDP (i.e., the Phillips curve). For all three tests, the case with competitive markets provides the best fit to the data, while the variant with trading frictions features the worse fit. The difference in performance across environments stems mainly from the idiosyncratic properties of the money demand, specifically how it responds to productivity shocks.

The paper follows in the tradition of Barro (1979) and Lucas and Stokey (1983), in which the role of government debt is to smooth tax distortions over time. The standard approach, which relies on the assumption that the government can commit to future policy choices, offers valuable normative insights, but is problematic as positive theory. In general, with commitment, the policy prescription is time-inconsistent, long-run debt levels are indeterminate and the predicted behavior of taxes and nominal interest rates is counterfactually smooth. As argued in Martin (2009) and Martin (2011b), relaxing the commitment assumption resolves these issues and allows the theory to help explain actual policy. The former paper studies government policy with limited commitment in a cash-in-advance economy, while the latter characterizes policy in the Lagos-Wright framework, for the competitive markets case with no aggregate uncertainty, as described above.

The recent literature on government policy under limited commitment follows the work of Klein et al. (2008) who characterize Markov-perfect equilibria in a model of optimal taxation. In addition to Martin $(2009,2011 b)$, several other papers study fiscal and monetary policy within this context. Díaz-Giménez et al. (2008) compare economies with real vs. nominal debt, with and without commitment, and evaluate the welfare implications of these different institutional arrangements. Niemann, Pichler and Sorger (2009) analyze the properties inflation dynamics under the assumptions of limited commitment and price rigidities. Niemann (2011) studies the effects of monetary conservatism and fiscal impatience in the determination of debt. Martin (2011a) studies the response of government policy to war-expenditure shocks and evaluates the model in terms of the U.S. experience.

Other related work includes studies of optimal policy in the Lagos-Wright framework. Gomis-Porqueras and Peralta-Alva (2009) abstract from government debt and show that fiscal policy can alleviate inefficiencies due to Nash bargaining in monetary trade. Aruoba and 
Chugh (2010) study optimal policy with commitment and compare their results with Chari et al. (1991), which study a cash-in-advance economy.

There are several proposed alternative mechanisms for the determination of the level of debt, which however, abstract from monetary policy. Battaglini and Coate (2008) show that inefficiencies due to pork-barrel spending provide an explanation for the distribution of (real) debt in the long-run. Barseghyan et al. (2010) develop the implications of Battaglini and Coate (2008) for the response of fiscal policy to productivity shocks at business cycles frequencies. Diamond (1965), Aiyagari and McGrattan (1998) and Shin (2006) provide a role for debt by using it to reduce dynamic inefficiencies.

The paper is organized as follows. Section 2 presents the general monetary framework. Section 3 characterizes government policy and derives theoretical results that hold in any monetary economy consistent with the basic framework. All proofs are contained in the appendix. Section 4 evaluates numerically the properties of long-run policy across three specific environments. Section 5 compares the properties of government policy in the presence of aggregate shocks. Section 6 concludes.

\section{A Monetary Framework}

\subsection{Environment}

Consider the following class of monetary economies, in the context of the framework proposed by Lagos and Wright (2005). There is a continuum of infinitely-lived agents. Each period, two markets open in sequence: a day and a night market. In each stage a perishable good is produced and consumed. At the beginning of each period, agents receive an idiosyncratic shock that determines their role in the day market. With probability $\eta \in(0,1)$ an agent wants to consume but cannot produce the day-good, $x$, while with probability $1-\eta$ an agent can produce but does not want consume. A consumer derives utility $u(x)$, where $u$ is twice continuously differentiable, with $u_{x}>0>u_{x x}$. A producer incurs in utility cost $f(x)$, where $f$ is twice continuously differentiable, with $f_{x}>0$ and $f_{x x} \geq 0$. Suppose there exists $\hat{x} \in(0, \infty)$ such that $u_{x}(\hat{x})=f_{x}\left(\frac{\eta \hat{x}}{1-\eta}\right)$.

Agents lack commitment and are anonymous, in the sense that private trading histories are unobservable. Thus, credit transactions between agents are not possible. Since the day market features lack of double coincidence of wants, some medium of exchange is essential for trade to occur - see Kocherlakota (1998), Wallace (2001) and Shi (2006).

At night, all agents can produce and consume the night-good, $c$. The production technology is assumed to be linear in hours worked, $n$. Utility from consumption is given by $U(c)$, where $U$ is twice continuously differentiable, satisfies Inada conditions and $U_{c}>0>U_{c c}$. Disutility from labor is given by $\alpha n$, where $n$ is hours worked and $\alpha>0$. Let $\hat{c} \in(0, \infty)$ such that $U_{c}(\hat{c})=\alpha$. Assume the following regularity condition holds: $U_{c c} c-\left(U_{c}-\alpha\right)\left(1+\frac{U_{c c c} c}{U_{c c}}\right)<0$ for all $c \in(0, \hat{c}]$-note that the typically adopted $U(c)=\frac{c^{1-\rho}}{1-\rho}$, with $\rho>0$, satisfies this requirement.

There is a benevolent government that supplies a valued public good $g$ at night. To finance its expenditure, the government may use proportional labor taxes $\tau$, print fiat money at rate $\mu$ and issue one-period nominal bonds, which are redeemable in fiat money. The public good is transformed one-to-one from the night-good. Agents derive utility from the public good according to $v(g)$, where $v$ is twice continuously differentiable, satisfies Inada conditions and $v_{g}>0>v_{g g}$. Let $\hat{g} \in(0, \infty)$ such that $v_{g}(\hat{g})=\alpha$.

The government announces period policy $\left\{B^{\prime}, \mu, \tau, g\right\}$ at the beginning of the day, before 
agents' idiosyncratic shocks are realized. It commits to this policy within the period, but lacks the ability to commit to future policy choices. The government only actively participates in the night-market, i.e., taxes are levied on hours worked at night and open market operations are conducted in the night market. As in Aruoba and Chugh (2010), Berentsen and Waller (2008) and Martin (2011b), public bonds are book-entries in the government's record. Since bonds are not physical objects and the government does not participate in the day market (i.e., cannot intermediate or provide third-party verification), bonds are not used as a medium of exchange in the day market and thus, money is essential.

All nominal variables - except for bond prices - are normalized by the aggregate money stock. Thus, today's aggregate money supply is equal to 1 and tomorrow's is $1+\mu$. The government budget constraint is

$$
1+B+p g=p \tau n+(1+\mu)\left(1+q B^{\prime}\right),
$$

where $B$ is the current aggregate bond-money ratio, $p$ is the - normalized-market price of the night-good $c$, and $q$ is the price of a bond that earns one unit of fiat money in the following night market. "Primes" denote variables evaluated in the following period. Thus, $B^{\prime}$ is tomorrow's aggregate bond-money ratio.

\subsection{The night market}

An agent arrives to the night market with individual money balances $m$ and government bonds $b$. Since bonds are redeemed in fiat money at par, the composition of an agent's nominal portfolio at the beginning of the night is irrelevant. Let $z \equiv m+b$, i.e., total-normalized-nominal holdings. The budget constraint of an agent at night is

$$
p c+(1+\mu)\left(m^{\prime}+q b^{\prime}\right)=p(1-\tau) n+z .
$$

Let $V(m, b)$ be the value of entering the day market with money balances $m$ and bond balances $b$, and let $W(z)$ be the value of entering the night market with total nominal balances $z$. After solving $n$ from (2), the problem of an agent in the night market is

$$
W(z)=\max _{c, m^{\prime}, b^{\prime}} U(c)+v(g)-\frac{\alpha c}{(1-\tau)}+\frac{\alpha\left(z-(1+\mu)\left(m^{\prime}+q b^{\prime}\right)\right)}{p(1-\tau)}+\beta V\left(m^{\prime}, b^{\prime}\right) .
$$

The first-order conditions are

$$
\begin{aligned}
U_{c}-\frac{\alpha}{(1-\tau)} & =0 \\
-\frac{\alpha(1+\mu)}{p(1-\tau)}+\beta V_{m}^{\prime} & =0 \\
-\frac{\alpha q(1+\mu)}{p(1-\tau)}+\beta V_{b}^{\prime} & =0 .
\end{aligned}
$$

Focusing on a symmetric equilibrium, we can follow Lagos and Wright (2005) to show that (4) and (5) imply all agents exit the night market with the same money and bond balances: $m^{\prime}=1$ and $b^{\prime}=B^{\prime}{ }^{3}$ The night aggregate resource constraint is $c+g=n$, where $n$ is aggregate labor. Note that private consumption $c$ and public consumption $g$ are the same for all agents, whereas individual labor depends on whether an agent was a consumer or a producer during the day. The night-value function $W$ is linear, $W_{z}=\frac{\alpha}{p(1-\tau)}$. We also get

$$
q=\frac{V_{b}^{\prime}}{V_{m}^{\prime}} .
$$

\footnotetext{
${ }^{3}$ Since $V$ is linear in $b$, a non-degenerate distribution of bonds is possible in equilibrium. Here, we focus on symmetric equilibria. See Aruoba and Chugh (2010) and Martin (2011b) for related discussions.
} 


\subsection{The day market}

During the day, consumers and producers exchange money for goods. The day-resource constraint is $\eta x=(1-\eta) \kappa$, where $x$ is the individual quantity consumed and $\kappa$ the individual quantity produced. The terms of trade depend on the details of the day-market. For example, trade can be decentralized or centralized, there may be financial institutions that intermediate money from producers to consumers, etc. The focus of this paper is on how different day-market specifications affect the predictions for government policy. The following assumption restricts the set of monetary economies I will be analyzing.

Assumption 1 In the day-market, in a monetary equilibrium: (i) the producer's problem is characterized by $\Phi(x)=W_{z}$, where $\Phi$ is continuously differentiable, $\Phi(x)>0, \Phi_{x}>0$ and $\Phi_{x x} \geq 0$ for all $x>0$; and (ii) $\Omega(x)=V_{m}-W_{z}$, where $\Omega$ is continuously differentiable, $\Omega(x)>0$ for all $x \in(0, \hat{x}), \Omega(\hat{x})=0, \Omega_{x}(\hat{x})<0$, and $\Omega(x)<0$ for all $x>\hat{x}$.

Assumption 1(i) states the production decision in equilibrium. $W_{z}$ is the real marginal benefit of arriving at night with an extra unit of nominal assets. The function $\Phi(x)$ represents the marginal utility cost for a producer, expressed in terms of day-purchasing power. Since producers get compensated with money for their production costs, these two expressions should be equated in equilibrium. The specific functional form of $\Phi(x)$ depends on how the terms of trade are determined, and is obtained after applying the day-resource constraint and corresponding market clearing conditions (which is why it does not depend on $\kappa$ or $z$ ). Note that $\Phi(x)$ is strictly increasing in $x$ which simply means that higher production is associated with a higher marginal value of money. Given the expression for $W_{z}$, we obtain the following condition

$$
\Phi(x)=\frac{\alpha}{p(1-\tau)} .
$$

Assumption 1(ii) states that, in equilibrium, the shadow value of liquidity in the day market is a function of day-good output, as determined by $\Omega(x)$, which is also obtained after applying the day-resource constraint and corresponding market clearing conditions. As I discuss in the following section, an important restriction here is that monetary trade in the day-market can be efficient, i.e, $\Omega(\hat{x})=0$. The properties of the function $\Omega(x)$ also allow for the existence of monetary equilibria where the allocation of the day good is below the efficient level.

Lemma 1 In a monetary equilibrium: (i) $V_{m}=\Omega(x)+\Phi(x)$; (ii) $V_{b}=\Phi(x)$; (iii) $\Omega(x) \geq 0$; (iv) consumers spend all their money holdings in the day-market.

All proofs are in Appendix A. Intuitively, parts (i) and (ii) of Lemma 1 follow from the fact that since bonds are not used as means of payment in day, their marginal value in the day and night markets need to be equal in equilibrium. Part (iii) obtains since for money to be valued in equilibrium, it needs to provide a liquidity service in the day market. By (6), this result also guarantees the nominal interest rate is non-negative in equilibrium, i.e., $q \leq 1$. Part (iv) is a standard result in this class of economies: if $V_{m}>W_{z}$ (i.e., $x<\hat{x}$ ), then the value of money is too high which means consumers are cash-constrained; if $V_{m}=W_{z}$ (i.e., $x=\hat{x}$ ), there is no opportunity cost of holding money and consumers spend all their cash without loss of generality. 
We can now collect the conditions that characterize a monetary equilibrium. After some rearrangement, (3), (4), (6) and (7) can be written as

$$
\begin{aligned}
\mu & =\frac{\beta\left(\Omega\left(x^{\prime}\right)+\Phi\left(x^{\prime}\right)\right)}{\Phi(x)}-1 \\
\tau & =1-\frac{\alpha}{U_{c}} \\
p & =\frac{U_{c}}{\Phi(x)} \\
q & =\frac{\Phi\left(x^{\prime}\right)}{\Omega\left(x^{\prime}\right)+\Phi\left(x^{\prime}\right)} .
\end{aligned}
$$

A monetary economy within this framework is thus spanned by a pair $\{\Phi(x), \Omega(x)\}$.

\section{Government Policy}

\subsection{Problem of the government}

As mentioned above, the government lacks the ability to commit to future policy choices and announces policy $\left\{B^{\prime}, \mu, \tau, g\right\}$ at the beginning of each period, after observing the level of inherited debt, $B$. To characterize government policy with limited commitment, I adopt the notion of Markov-perfect equilibrium, i.e., where policy functions depend only on fundamentals. ${ }^{4}$

The literature on optimal policy typically applies what is known as the primal approach, which consists of using the first-order conditions of the agent's problem to substitute prices and policy instruments for allocations in the government budget constraint. Following this approach, the problem of a government with limited commitment can be written in terms of choosing debt and allocations, as described below.

Using the night-resource constraint, $c+g=n$, and conditions (8)-(11), we can write the government budget constraint in a monetary equilibrium as

$$
\left(U_{c}-\alpha\right) c-\alpha g+\beta \Omega\left(\mathcal{X}\left(B^{\prime}\right)\right)+\beta \Phi\left(\mathcal{X}\left(B^{\prime}\right)\right)\left(1+B^{\prime}\right)-\Phi(x)(1+B)=0,
$$

where $\mathcal{X}\left(B^{\prime}\right)$ is the day-good allocation that the current government anticipates its future-self will implement as a function of inherited debt. Due to the limited commitment friction, the government today takes this policy function as given.

Notice that from (8), for a given $x^{\prime}=\mathcal{X}\left(B^{\prime}\right)$, a higher $\mu$ implies a lower $x$, since $\Phi(x)$ is strictly increasing. In other words, given current debt policy and future monetary policy, the allocation of the day-good is a function of current monetary policy. Thus, we can interchangeably refer to variations in the day-good allocation and variations in current monetary policy. Similarly, from (9) a higher tax rate is equivalent to lower night-good consumption, $c$.

The problem of the current government is to choose $B^{\prime}, x, c$ and $g$ in order to maximize agents' present value utility. The government is constrained to satisfy its period budget constraint in a monetary equilibrium, as determined by (12) and Lemma 1(iii), anticipating that future policy will react to the level of inherited nominal liabilities. Let $\Gamma \in[-1, \bar{B}]$ be the set of possible debt levels, where $\bar{B}$ is large enough so that it does not constrain government behavior. The lower bound on $\Gamma$ is not restrictive, as shown in Proposition 1(iv) below.

\footnotetext{
${ }^{4}$ See Maskin and Tirole (2001) for a definition and justification of this solution concept. For recent applications to dynamic policy games see Ortigueira (2006), Klein et al. (2008), Díaz-Giménez et al. (2008), Martin (2009, 2010, 2011b), Azzimonti et al. (2009) and Niemann (2011), among others.
} 
Given $B$ and the perception that future governments implement $\mathcal{X}(B)$, the problem of the current government is

$$
\max _{B^{\prime}, x, c, g} \eta u(x)-(1-\eta) f(\kappa)+U(c)+v(g)-\alpha(c+g)+\beta \mathcal{V}\left(B^{\prime}\right)
$$

subject to (12), $\Omega(x) \geq 0$ and where $\kappa=\frac{\eta x}{1-\eta}$ by the day-resource constraint. Government policy in equilibrium is defined as follows.

Definition 1 A Markov-Perfect Monetary Equilibrium $(M P M E)$ is a set of functions $\{\mathcal{B}, \mathcal{X}, \mathcal{C}, \mathcal{G}, \mathcal{V}\}$ : $\Gamma \rightarrow \Gamma \times \mathbb{R}_{+}^{3} \times \mathbb{R}$, such that for all $B \in \Gamma$ :

$(i)\{\mathcal{B}(B), \mathcal{X}(B), \mathcal{C}(B), \mathcal{G}(B)\}=\underset{B^{\prime}, x, c, g}{\operatorname{argmax}} \eta u(x)-(1-\eta) f\left(\frac{\eta x}{1-\eta}\right)+U(c)+v(g)-\alpha(c+g)+\beta \mathcal{V}\left(B^{\prime}\right)$

subject to (12) and $\Omega(x) \geq 0$; and

$($ ii $\left.) \mathcal{V}(B)=\eta u(\mathcal{X}(B))-(1-\eta) f\left(\frac{\eta \mathcal{X}(B)}{1-\eta}\right)+U(\mathcal{C}(B))+v \mathcal{G}(B)\right)-\alpha(\mathcal{C}(B)+\mathcal{G}(B))+\beta \mathcal{V}(\mathcal{B}(B))$

\subsection{Characterization}

Assume the policy function $\mathcal{X}(B)$ followed by future governments is differentiable. ${ }^{5}$ Let $\lambda$ and $\zeta$ be the Lagrange multiplier associated with the constraints of the government's problem. Given $\mathcal{V}_{B}=-\lambda \Phi(x)$ and $\lambda^{\prime}=\Lambda\left(B^{\prime}\right)$, the first-order conditions are

$$
\begin{aligned}
\Phi\left(\mathcal{X}\left(B^{\prime}\right)\right)\left[\lambda-\Lambda\left(B^{\prime}\right)\right]+\lambda \mathcal{X}_{B}^{\prime}\left[\Omega_{x}^{\prime}+\Phi_{x}^{\prime}\left(1+B^{\prime}\right)\right] & =0 \\
\eta\left(u_{x}-f_{\kappa}\right)-\lambda \Phi_{x}(1+B)+\zeta \Omega_{x} & =0 \\
U_{c}-\alpha+\lambda\left(U_{c}-\alpha+U_{c c} c\right) & =0 \\
-\alpha+v_{g}-\lambda \alpha & =0 .
\end{aligned}
$$

The following statement establishes some important properties of the equilibrium.

Proposition 1 In a $M P M E$, for all $B \in \Gamma$ : (i) $\Lambda(B)>0$; (ii) $\zeta(B)=0$; (iii) $\mathcal{X}_{B}<0$; and (iv) $\mathcal{B}(B)>-1$ and $q(B)<1$.

The intuition for Proposition 1(i) is that, given the incentives to smooth distortions over time, the government will not implement the first-best allocation in the current period if there are expected distortions in the future. In order to eliminate policy distortions, the government needs to: contract the money supply at rate $\beta-1$; impose zero taxes; and provide the first-best level of expenditure. In principle, there are two ways it could achieve this. First, the government could start with sufficient claims on the private sector (negative debt) to implement the firstbest. The level of steady state debt that implements the first-best policy is $\hat{B}=-1-\frac{\alpha \hat{g}}{(1-\beta) \Phi(\hat{x})}$, which is outside of $\Gamma$. A second possibility is that the government implements the first-best allocation by continually rolling over the debt. This policy is inconsistent with equilibrium, as shown in the proof - see Appendix A. From (9) and (15), $\lambda>0$ implies $\tau>0$, i.e., tax rates are always positive, for all levels of debt. Similarly, from (16) the public good provision is always below the efficient level.

\footnotetext{
${ }^{5}$ This is a refinement that rules out equilibria where discontinuities in policy are not rooted in the environment fundamentals, but are rather an artifact of the infinite horizon. For an analysis and discussion of non-differentiable Markov-perfect equilibria see Krusell and Smith (2003) and Martin (2009). See also Martin (2011b) for further discussion in a similar context.
} 
Proposition 1(ii) establishes that the non-negativity constraint $\Omega(x) \geq 0$ does not bind for any $B \in \Gamma$. This result relies on Assumption 1(ii), i.e., that the efficient allocation in the daymarket can be achieved through monetary trade. Monetary economies where this assumption does not hold, may very well feature $\mathcal{X}(B)=\bar{x}<\hat{x}$ for all $B \in \Gamma$ - see Appendix B.4 for an example.

Proposition 1(iii) rules out the possibility that the day-good allocation could be (weakly) increasing in debt. This would be inconsistent with an equilibrium since it would imply the government could increase debt and welfare at the same time, which in turn would mean it is not constrained by a budgetary restriction, a contradiction with Proposition 1(i). In equilibrium, we obtain $\mathcal{X}(-1)=\hat{x}$ and $\mathcal{X}(B)<\hat{x}$ for all $B>-1$.

Finally, Proposition 1(iv) offers two important results. First, $\mathcal{B}(B)>-1$, which means the government always chooses to carry over strictly positive net nominal liabilities (money plus bonds). Second, the Friedman rule of zero nominal interest rate $(q=1)$ is not implemented in equilibrium, for any level of debt.

\subsection{Determination of government policy}

The presence of the derivative of the equilibrium function $\mathcal{X}(B)$ in (13) reflects a time-consistency problem, as the government tomorrow will not internalize how its policy affected current actions. In equilibrium, government policy results from the interaction between monetary policy and government debt. This interaction introduces both intratemporal and intertemporal tradeoffs.

First, the government has an incentive to inflate away its inherited nominal liabilities, at the cost of distorting the allocation of the day-good. Given $\lambda>0$ and $\zeta=0$ by Proposition 1 , condition (14) states that an increase in beginning-of-period debt, $B$, implies a decrease in day-good consumption, $x$. In other words, the incentive to use inflation increases with the level of debt and thus, $\mathcal{X}_{B}<0$. This is the channel through which debt affects monetary policy.

Second, the government faces an intertemporal trade-off, as stated in (13). The term $\Phi\left(\mathcal{X}\left(B^{\prime}\right)\right)\left[\lambda-\Lambda\left(B^{\prime}\right)\right]$ is the standard trade-off between current and future distortions, and is the basis for the classic tax-smoothing argument, due to Barro (1979), which involves setting this wedge to zero. The government's limited commitment introduces an additional term, $\lambda \mathcal{X}_{B}^{\prime}\left[\Omega_{x}^{\prime}+\Phi_{x}^{\prime}\left(1+B^{\prime}\right)\right]$. From Lemma 1, we have $\Omega(x)+\Phi(x)(1+B)=V_{m}+V_{b} B$ and so, $\Omega_{x}^{\prime}+\Phi_{x}^{\prime}\left(1+B^{\prime}\right)=\frac{d V_{m}^{\prime}}{d x^{\prime}}+\frac{d V_{b}^{\prime}}{d x^{\prime}} B^{\prime}$. Given $\lambda \mathcal{X}_{B}^{\prime}<0$ by Proposition 1, the sign of this last expression will determine how policy distortions are substituted intertemporally, i.e., how debt evolves over time.

To facilitate the argument, suppose the model primitives are such that $\frac{d V_{m}}{d x}=\Omega_{x}+\Phi_{x}<0$ and focus on $B>0$. On the one hand, if the government increases the debt today, $\frac{d V_{m}^{\prime}}{d x^{\prime}} \mathcal{X}_{B}^{\prime}>0$ implies there is an increase in tomorrow's marginal value of money. I.e., agents tomorrow, facing higher inflation due to higher debt, would have preferred to have arrived with more money. Thus, the current demand for money increases, which relaxes the government budget constraint today. On the other hand, since $\Phi_{x}>0, \frac{d V_{b}^{\prime}}{d x^{\prime}} \mathcal{X}_{B}^{\prime}<0$, i.e., increasing debt today implies higher future inflation, which reduces the current demand for bonds. In other words, the interest rate paid on debt increases, which tightens the government budget constraint. For low levels of debt, the former effect dominates, providing an incentive to increase the debt, whereas for large levels of debt the latter effect dominates, providing an incentive to decrease debt. The gains from these incentives are offset by the losses due to lower intertemporal distortion smoothing, i.e., a larger wedge $\lambda-\Lambda\left(B^{\prime}\right)$. 


\subsection{Long-run debt}

In steady state, $(13)$ simplifies to $\Omega_{x}^{*}+\Phi_{x}^{*}\left(1+B^{*}\right)=0$, since $\lambda \mathcal{X}_{B}<0$ for all $B \in \Gamma$ by Proposition 1. A steady state $\left\{B^{*}, x^{*}, c^{*}, g^{*}\right\}$ is characterized by

$$
\begin{aligned}
B^{*} & =-\frac{\Omega_{x}^{*}}{\Phi_{x}^{*}}-1 \\
\alpha \eta\left(u_{x}^{*}-f_{\kappa}^{*}\right)+\left(v_{g}^{*}-\alpha\right) \Omega_{x}^{*} & =0 \\
v_{g}^{*}\left(U_{c}^{*}-\alpha\right)+\left(v_{g}^{*}-\alpha\right) U_{c c}^{*} c^{*} & =0 \\
\left(U_{c}^{*}-\alpha\right) c^{*}-\alpha g^{*}+\beta \Omega^{*}(x)+\frac{(1-\beta) \Phi\left(x^{*}\right) \Omega_{x}^{*}}{\Phi_{x}^{*}} & =0 .
\end{aligned}
$$

Thus, even though from (13) the MPME depends globally on the derivative of the $\mathcal{X}(B)$ function, the steady state can be solved locally. The proposition below relates long-run debt with environment primitives, which will be useful when calibrating specific economies

Proposition 2 Positive long-run debt. $B^{*}>0$ if and only if $\Omega_{x}^{*}+\Phi_{x}^{*}<0$.

In the specific monetary economies analyzed in subsequent sections, the condition $\Omega_{x}+\Phi_{x}<$ 0 can be satisfied given sufficiently high curvature on the day-good utility function.

Although small changes in debt choice at $B^{*}$ still have an effect on future policy, since $\mathcal{X}_{B}^{*}<0$, the positive and negative effects of these changes on the current government budget constraint are balanced out. In other words, the time-consistency problem, which is driving the change in debt, cancels out at the steady state. It follows that if the governments starts at $B^{*}$, it will stay there, regardless of its ability to commit. The following proposition generalizes the result in Martin (2011b).

Proposition 3 Irrelevance of commitment at $B^{*}$. Suppose initial debt is equal to $B^{*}$; then, a government with commitment and a government without commitment will both implement the allocation $\left\{x^{*}, c^{*}, g^{*}\right\}$ and choose debt level $B^{*}$ in every period.

Thus, the steady state is constrained-efficient, since endowing the government with commitment at $B^{*}$ would not affect the allocation. This is an important property of this monetary framework: limited commitment by the government provides a mechanism that explains the level of debt and thus, policy in general, but is not a primary concern in terms of institutional design and welfare. Another implication is that time-consistency of the optimal (commitment) policy is not necessarily linked to the optimality of the Friedman rule, as previously suggested by the results in Alvarez et al. (2004). At $B^{*}$ there is no time-consistency problem, even though the government is inflating away its nominal liabilities.

The last result in this section establishes conditions under which distinct monetary economies share similar properties in the long-run.

Proposition 4 Equivalence of monetary economies. Consider a set of distinct monetary economies: $\left\{\Omega^{i}(x), \Phi^{i}(x)\right\}_{i=1}^{n}, n>1$. Assume $\Omega^{i}(x)=\Omega^{j}(x)$ and $\frac{\Phi^{i}(x)}{\Phi_{x}^{i}}=\frac{\Phi^{j}(x)}{\Phi_{x}^{j}}$, for all $\{i, j\}$. Then: (i) $\left\{x^{i *}, c^{i *}, g^{i *}, \tau^{i *}\right\}=\left\{x^{j *}, c^{j *}, g^{j *}, \tau^{j *}\right\}$; (ii) $\left\{B^{i *}, \mu^{i *}, q^{i *}\right\} \neq\left\{B^{j *}, \mu^{j *}, q^{j *}\right\}$; and (iii) if $\Phi^{i}(x)<\Phi^{j}(x)$ then $B^{i *}>B^{j *}, \mu^{i *}>\mu^{j *}$ and $q^{i *}<q^{j *}$.

Economies that feature the same shadow value of liquidity in the day market, plus some notion of proportionality in the incentives to produce the day-good, will share the same longrun allocation and taxes. However, debt and inflation will be higher in the economy where the 
incentives to produce are higher, i.e., $\Phi(x)$ is lower. In such a case, the costs associated with future monetary policy distortions are lower as well and thus, the government's incentives to issue debt are higher. Given the larger debt, long-run inflation ends up being higher, due to the higher financial burden.

\section{Evaluation}

\subsection{Three monetary economies}

Consider three distinct day-market specifications for the framework analyzed above. The first monetary economy, "competitive markets", assumes consumers and producers in the day trade goods for money in competitive markets. The second, "financial intermediation" expands on the previous economy by allowing banks to intermediate money from producers to consumers. The third, "trading frictions" assumes trade is decentralized, with buyers and sellers trading in bilateral meetings and no financial intermediation. In this last case, the measure of buyers and sellers is the same $\left(\eta=\frac{1}{2}\right)$ and the trading surplus is split according to the proportional solution due to Kalai (1977), with buyer's bargaining weight $\theta \in(0,1]$,

The economy with financial intermediation has only those frictions necessary to make a medium of exchange essential: lack of double coincidence of wants, imperfect record keeping and limited commitment. The case with competitive markets adds a financial friction which precludes the intermediation of fiat money in the day market. Finally, the case with trading frictions features the most number of frictions, both financial and trading.

Table 1 summarizes the three economies described above by specifying the corresponding functional forms for $\Phi(x)$ and $\Omega(x)$. These expressions are derived formally in Appendix B.

Table 1: Monetary economies

\begin{tabular}{|c|c|c|c|}
\hline Variable & $\begin{array}{c}\text { Competitive } \\
\text { Markets }\end{array}$ & $\begin{array}{c}\text { Financial } \\
\text { Intermediation }\end{array}$ & $\begin{array}{c}\text { Trading } \\
\text { Frictions }\end{array}$ \\
\hline$\Phi(x)$ & $f_{\kappa} x$ & $\eta f_{\kappa} x$ & $(1-\theta) u(x)+\theta f(x)$ \\
$\Omega(x)$ & $\eta x\left(u_{x}-f_{\kappa}\right)$ & $\eta x\left(u_{x}-f_{\kappa}\right)$ & $\frac{\theta \Phi(x)\left(u_{x}-f_{x}\right)}{2 \Phi_{x}}$ \\
\hline
\end{tabular}

Note: By the day-resource constraint $\kappa=\frac{\eta x}{1-\eta}$. In the economy with trading frictions, $\eta=\frac{1}{2}$.

The critical parameters that differentiate the three monetary economies are $\eta$ and $\theta$. The cases with competitive markets and financial intermediation become more similar as the measure of consumers $\eta$ increases. The reason is that banks channel money balances from producers to consumers and this effect becomes less prominent as the measure of producers decreases. Assuming $\eta=\frac{1}{2}$ and $f(x)$ linear in $x$, the case with trading frictions approaches the competitive markets solutions as $\theta \rightarrow 1$.

Note that the economies with competitive markets and financial intermediation satisfy the assumptions in Proposition 4. Thus, given the same parameterization, both these economies exhibit the same long-run allocation $\left\{x^{*}, c^{*}, g^{*}\right\}$ and the same long-run tax rates, but differ in the level of debt, the money growth rate and the nominal interest rate. In particular, since $\Phi(x)$ is lower for the case with financial intermediation, steady state debt and inflation are higher with financial intermediation than competitive markets, while the nominal interest rate is lower. These results inform us of what would happen to government policy if we were to resolve financial frictions in the competitive markets economy - see below for a quantitative 
assessment.

\subsection{Calibration}

Let us calibrate the steady state of each environment. Consider the following functional forms:

$$
\begin{aligned}
u(x) & =\left\{\begin{array}{cll}
\frac{x^{1-\sigma}}{1-\sigma} & \text { if } & \bar{x}=0 \\
\frac{(x+\bar{x})^{1-\sigma}-\bar{x}^{1-\sigma}}{1-\sigma} & \text { if } & \bar{x}>0
\end{array}\right. \\
f(x) & =\phi x \\
U(c) & =\frac{c^{1-\rho}}{1-\rho} \\
v(g) & =\psi \ln g .
\end{aligned}
$$

When there are no trading frictions we set $\bar{x}=0$, so that $u(x)$ is standard CES; for the case with trading frictions we need $\bar{x}>0$ since bargaining requires a positive surplus and thus, $u(0)=0$. For now, normalize $\psi=1$ and set $\eta=\frac{1}{2}$. The parameters left to calibrate are $\alpha, \beta, \rho, \sigma, \phi, \theta$ and $\bar{x}$.

Define nominal GDP as the sum of nominal output in the day and night markets. Let $Y$ be nominal GDP normalized by the aggregate money stock, i.e., $Y \equiv \eta \tilde{p} x+p(c+g)$, where $\tilde{p}$ is the (normalized) price of the day-good - see Appendix B. Note that by the equation of exchange, $Y$ is also equal to velocity of circulation. For the case with competitive markets, $\tilde{p} x=1$ and thus, $Y=\eta+p(c+g)$. With financial intermediation, $\tilde{p} x=\frac{1}{\eta}$ and thus, $Y=1+p(c+g)$. With trading frictions, note that the implicit price in all bilateral meetings is $\frac{1}{x}$; thus, $Y$ is the same as with competitive markets. For the cases with competitive markets and trading frictions, the night market is $91 \%$ of total GDP; with financial intermediation, the relative size of the night market drops to $82 \%$.

Calibration targets are taken from 1962-2006 averages for the U.S. economy. Period length is set to a year. Government in the model corresponds to the federal government. The calibration targets are: debt over GDP, annual inflation, interest payment over GDP, outlays (excluding interest) over GDP and revenues over GDP. Inflation is measured from the CPI, while the rest of the variables are taken from the Congressional Budget Office. Government debt is defined as debt held by the public, excluding holdings by the Federal Reserve system.

Next, we need to specify the model steady state statistics that correspond to the selected calibration targets. For debt over GDP use $\frac{B(1+\mu)}{Y}$, since debt is measured at the end of the period in the data. Let $\pi$ be annual inflation in the model, which in steady state is equal to $\mu$. Interest payments over GDP are defined as $\frac{B(1+\mu)(1-q)}{Y}$. Given that debt over GDP is already targeted, this implies a target for the nominal interest rate $i$, where $i=\frac{1}{q}-1$. Interest payments are $2.1 \%$ of GDP in the data, which implies a target nominal interest rate of $7.3 \%$ annual. Outlays and revenues are defined as $\frac{p g}{Y}$ and $\frac{p \tau n}{Y}$, respectively, where $n=c+g$ from the night-resource constraint. For the case with trading frictions, the typical approach is to include an additional target, the price-to-marginal cost ratio or markup. ${ }^{6}$ Since the markup in the night-market is zero, the markup is equal to the share of the day-market output in GDP times the day-market markup. Let $\omega$ be the markup, where $\omega \equiv \frac{\eta(1-\theta)}{Y}\left(\frac{u(x)}{\phi x}-1\right)$. I use the usual target adopted by the literature, $10 \%$. Table 2 summarizes the target statistics.

Table 3 shows the parameters that match the calibration targets for each of the environments considered. As mentioned above, for the cases with no trading frictions, $\bar{x}=0$. For the case with trading frictions, $\bar{x}=0.5$ and $\theta$ is set equal to 0.8739 to match the markup, $\omega$. The value of $\bar{x}$ is

\footnotetext{
${ }^{6}$ See Lagos and Wright (2005) and Aruoba et al. (2011) for further discussion.
} 
Table 2: Target statistics

\begin{tabular}{|c|c|c|c|c|c|}
\hline$\frac{B^{*}\left(1+\mu^{*}\right)}{Y^{*}}$ & $\pi^{*}$ & $i^{*}$ & $\frac{p^{*} \tau^{*} n^{*}}{Y^{*}}$ & $\frac{p^{*} g^{*}}{Y^{*}}$ & $\omega^{*}$ \\
\hline 0.308 & 0.044 & 0.073 & 0.182 & 0.182 & 0.100 \\
\hline
\end{tabular}

Note: $\omega$ is a calibration target only for the case with trading frictions.

much higher than the typically found in the literature (which is close to zero, say $\bar{x}=0.0001$ ). The reasons is that lower values of $\bar{x}$ imply higher values of $\theta$ to match the markup target (see the expression for $\omega$ above); e.g., if $\bar{x}=0.25$ then $\theta=0.9284$, and if $\bar{x}=0.005$ then $\theta=0.9989$. The benchmark value for $\bar{x}$ is a compromise between making the environment with trading frictions sufficiently different from the competitive markets case and not deviating too much from a standard CES utility specification. It is important to point out that the quantitative results reported in the sections below are not affected by the choice of $\bar{x}$. In particular, setting $\bar{x}=0.5$ (and recalibrating) for the cases without trading frictions or setting $\bar{x}=0.005$ (and recalibrating) for the case with trading friction have only minor quantitative effects that are not sufficiently significant to overturn any of the conclusions.

Table 3: Benchmark calibration

\begin{tabular}{|c|c|c|c|}
\hline Parameters & $\begin{array}{c}\text { Competitive } \\
\text { Markets }\end{array}$ & $\begin{array}{c}\text { Financial } \\
\text { Intermediation }\end{array}$ & $\begin{array}{c}\text { Trading } \\
\text { Frictions }\end{array}$ \\
\hline$\alpha$ & 4.9801 & 4.1722 & 5.1648 \\
$\beta$ & 0.9728 & 0.9728 & 0.9728 \\
$\rho$ & 7.3670 & 8.1879 & 6.4633 \\
$\sigma$ & 4.6965 & 2.5084 & 5.8405 \\
$\phi$ & 1.3332 & 4.8290 & 1.3701 \\
$\psi$ & 1.0000 & 1.0000 & 1.0000 \\
$\eta$ & 0.5000 & 0.5000 & - \\
$\theta$ & - & - & 0.8739 \\
$\bar{x}$ & 0.0000 & 0.0000 & 0.5000 \\
\hline
\end{tabular}

The steady state allocation $\left\{B^{*}, x^{*}, c^{*}, g^{*}\right\}$ is found by solving numerically the system of equations (17) - (20). Table 4 shows the solutions for all the cases considered.

Table 4: Steady state variables for benchmark calibration

\begin{tabular}{|l|c|c|c|}
\hline & $\begin{array}{c}\text { Competitive } \\
\text { Markets }\end{array}$ & $\begin{array}{c}\text { Financial } \\
\text { Intermediation }\end{array}$ & $\begin{array}{c}\text { Trading } \\
\text { Frictions }\end{array}$ \\
\hline$B^{*}$ & 1.619 & 1.619 & 1.619 \\
$x^{*}$ & 0.914 & 0.519 & 0.422 \\
$c^{*}$ & 0.780 & 0.814 & 0.749 \\
$g^{*}$ & 0.195 & 0.233 & 0.188 \\
\hline
\end{tabular}

\subsection{Comparative statics}

To further understand the differences in long-run policy across cases, we can analyze the response of steady state statistics to changes in parameter values. Each parameter is perturbed by $\pm 10 \%$. 
Next, the percentage change in a steady state statistic is divided by the percentage change in the parameter value, to measure the elasticity of the statistic to changes in parameters. Table 5 presents the results, highlighting elasticities between 0.25 and 1 , and elasticities above 1 , plus the sign of the change in statistics. ${ }^{7}$ See Appendix $\mathrm{C}$ for a table with the actual figures.

Table 5: Parameter-elasticity of steady state statistics

\begin{tabular}{|c|c|c|c|c|c|c|c|c|c|c|c|c|c|c|c|c|c|}
\hline & \multicolumn{6}{|c|}{ Competitive Markets } & \multicolumn{6}{|c|}{ Financial Intermediation } & \multicolumn{5}{|c|}{ Trading Frictions } \\
\hline & $\Delta \alpha$ & $\Delta \phi$ & $\Delta \eta$ & $\Delta \rho$ & $\Delta \sigma$ & $\Delta \psi$ & $\Delta \alpha$ & $\Delta \phi$ & $\Delta \eta$ & $\Delta \rho$ & $\Delta \sigma$ & $\Delta \psi$ & $\Delta \alpha$ & $\Delta \phi$ & $\Delta \rho$ & $\Delta \sigma$ & $\Delta \psi$ \\
\hline$\frac{B^{*}\left(1+\mu^{*}\right)}{Y^{*}}$ & - & + & ++ & - & ++ & & - & + & + & & ++ & & - & - & - & ++ & \\
\hline & - & & ++ & -- & ++ & ++ & - & & & -- & ++ & ++ & - & - & -- & ++ & ++ \\
\hline & - & & & & & + & - & & & & & + & - & & & & + \\
\hline$\frac{p^{*} \tau^{*} n^{*}}{Y^{*}}$ & - & & & & & + & - & & & & & + & - & & & & + \\
\hline$\frac{p^{*} g^{*}}{Y^{*}}$ & - & & & & & + & - & & & & & + & - & & & & + \\
\hline
\end{tabular}

Note: Each parameter is increased and then decreased by $10 \%$. Elasticity is measured as the percentage change in a statistic divided by 1.1/0.9 - 1, where the change in statistic corresponds to $\pm 10 \%$ change in parameter value. A positive (negative) sign implies the statistic increases (decreases) with an increase in parameter value. A single sign implies the elasticity is higher than 0.25 but lower than 1 ; a double sign implies the elasticity is equal to or higher than 1. For the case with trading frictions, $\Delta \eta$ is omitted since it is always assumed that $\eta=0.5$.

Let us first focus on the case with competitive markets. As we can see, only debt and inflation feature parameter-elasticities greater than 1: both variables are increasing in $\eta$ and $\sigma$; in addition, inflation also increases significantly with reductions in $\rho$ and increases in $\psi$. The remaining effects feature lower parameter-elasticities. In this sense, increases in $\alpha$ reduce debt, inflation, taxes, expenditure and revenue; increases in $\phi$ increase debt; and increases in $\psi$ increase taxes, expenditure and revenue.

The other two monetary economies feature some notable similarities with the competitive markets case. Most notably, the effect of changes in $\alpha$ and $\psi$ go in the same direction for all three variants; quantitatively, the effect is also very similar across model variants - see Appendix C. In all three cases, an increase in $\sigma$ implies a large increase in both debt and inflation. Quantitatively, the effect is significantly larger for the case with trading frictions.

There are two differences in comparative statics worth highlighting. For the case with financial intermediation, changes in $\eta$ affect debt, but not inflation. For the case with trading frictions, an increase in $\phi$ decreases both debt and inflation, in sharp contrast with the other two cases, which feature an increase in debt and no change in inflation.

The results in this section highlight the long-run interaction between fiscal and monetary policies. First, a higher demand for public goods (larger $\psi$ ) results in significantly higher inflation and taxes, but has very small effects on debt. This is consistent with the standard distortion-smoothing argument which states that permanent increases in expenditure should be finances with taxation. Second, the determinants of the money demand fundamentally affect debt and monetary policy. The expression $\frac{d V_{m}}{d x}$, which as analyzed above determines how the current demand for money reacts to change in future monetary policy, depends critically on $\eta$ and $\sigma$. The larger the response of money demand today to variations in future monetary policy, the larger the incentive to issue debt, which in turn results in higher inflation to alleviate its financial burden.

\footnotetext{
${ }^{7}$ The cut-off point of 0.25 is somewhat arbitrary. The idea is to focus on changes in long-run statistics which are sufficiently significant, given that the change in parameter values is $\frac{1.1}{0.9}-1 \approx 0.222$.
} 


\subsection{Frictions and long-run policy}

What are the effects on long-run policy of resolving the different frictions that afflict the environments studied above?

First, suppose we resolve trading frictions. Thus, take the parameterization for the case with trading frictions and solve the case with competitive markets. In steady state, debt over GDP decreases to $4.1 \%$, annual inflation drops to $1.7 \%$, while tax revenue and expenditure both increase slightly to about $19 \%$ of GDP. If we consider a higher bargaining power for consumers and recalibrate, the difference in statistics becomes even larger. The reason is that as we increase $\theta$ (lower $\bar{x}$ ), we need to reduce $\sigma$ to match the target statistics for the case with trading frictions. From (17) and Table 1, note that $B^{*}$ is increasing in $\sigma$ in all economies; thus, when we switch to the case with competitive markets, long-run debt (and thus, inflation) decreases even more.

Second, suppose we shut down the banking sector. Thus, take the parameterization for the case with financial intermediation and solve the case with competitive markets. From Proposition 4 we know that in the long-run, only debt, inflation and the nominal interest rate change; without banks, steady state debt over GDP decreases to $11.4 \%$, while annual inflation drops to $0.8 \%$. Note that the magnitude of these policy changes are inversely related to the assumed value for $\eta$. For example, set $\eta=0.8$ and recalibrate the economy with financial intermediation; thus, $\phi=2.2101$ while all other parameters remain at benchmark. If we now solve the steady state with competitive markets, we get debt over GDP of $25.7 \%$ and annual inflation of 3.0\%; i.e., the changes are significant, but not quite as dramatic as when $\eta=0.5$.

The analysis shows that resolving trading frictions reduces long-run debt and inflation, whereas resolving financial frictions has the opposite effect. The quantitative magnitude of these effects may be quite seizable. Given that with certain technological advances (e.g., electronic record keeping, automation), both goods markets and financial markets become more efficient, the results indicate that these improvements may have a significant impact on government policy. Recovering the contribution of these changes from the data may prove difficult as they have canceling effects. In addition, these institutional changes to not occur in isolation; e.g., technological advances that alleviate trading and financial frictions are likely to also improve labor productivity.

\section{Government Policy and Aggregate Uncertainty}

This section studies government policy in the presence of aggregate uncertainty. The focus is on understanding how policy response to aggregate shocks depends on the details of the monetary economy. I consider shocks to government expenditure and aggregate productivity and compare the model variants along four dimensions: the response of government policy to aggregate shocks; the persistence of policy variables; the money demand; and the Phillips curve.

\subsection{Government policy in monetary economies with aggregate uncertainty}

Suppose there are two aggregate shocks: one to the marginal value of the public good (an "expenditure" shock) and one to the productivity of labor. The utility derived from the public good is now $v(g)=\psi \nu(g)$, where $\nu_{g}>0>\nu_{g g}$ and $\psi$ is a random variable. Let $A$ be labor productivity, which affects both day and night output, and follows a random process. Thus, daygood producers incur a utility cost $f(x, A)$, where $f$ is strictly decreasing in $A$, and night-output is equal to $A n$.

Let $s \equiv\{\psi, A\}$ follow a Markov process and let $E\left[s^{\prime} \mid s\right]$ be the expected value of $s^{\prime}$ given 
$s$. The set of all possible realizations for the stochastic state is $S$. A monetary economy, as constructed in Section 2, in now spanned by functions $\Phi(x, s)$ and $\Omega(x, s)$. After solving for the monetary equilibrium, we can write the government budget constraint as

$$
\left(U_{c}-\frac{\alpha}{A}\right) c-\frac{\alpha g}{A}-\Phi(x, s)(1+B)+\beta E\left[\Omega\left(\mathcal{X}\left(B^{\prime}, s^{\prime}\right), s^{\prime}\right)+\Phi\left(\mathcal{X}\left(B^{\prime}, s^{\prime}\right), s^{\prime}\right)\left(1+B^{\prime}\right) \mid s\right]=0 .
$$

Given aggregate state $(B, s)$ and anticipating future governments will implement $\mathcal{X}(B, s)$, the problem of the current government is

$$
\max _{B^{\prime}, x, c, g} \eta u(x)-(1-\eta) f(\kappa, A)+U(c)-\frac{\alpha(c+g)}{A}+\psi \nu(g)+\beta E\left[\mathcal{V}\left(B^{\prime}, s^{\prime}\right) \mid s\right]
$$

subject to (21), where $\kappa=\frac{\eta x}{1-\eta}$ by the day-resource constraint. After some work, the first-order conditions imply

$$
\begin{aligned}
E\left[\Phi\left(\mathcal{X}\left(B^{\prime}, s^{\prime}\right), s^{\prime}\right)\left(A \psi \nu_{g}-A^{\prime} \psi^{\prime} \nu_{g}^{\prime}\right)+\left(A \psi \nu_{g}-\alpha\right) \mathcal{X}_{B}^{\prime}\left(\Phi_{x}^{\prime}+\Omega_{x}^{\prime}\left(1+B^{\prime}\right)\right) \mid s\right] & =0 \\
\alpha \eta\left(u_{x}-f_{\kappa}\right)-\left(A \psi \nu_{g}-\alpha\right) \Phi_{x}(1+B) & =0 \\
A \psi \nu_{g}\left(U_{c}-\frac{\alpha}{A}\right)+\left(A \psi \nu_{g}-\alpha\right) U_{c c} c & =0 .
\end{aligned}
$$

Definition $2 A M P M E$ in a stochastic economy is characterized by a set of functions $\{\mathcal{B}(B, s)$, $\mathcal{X}(B, s), \mathcal{C}(B, s), \mathcal{G}(B, s)\}: \Gamma \times S \rightarrow \Gamma \times \mathbb{R}_{+}^{3}$ that satisfy $(21)-(24)$, for all $(B, s) \in \Gamma \times S$.

The expressions for $\Phi(x, s)$ and $\Omega(x, s)$ are easily derived for each of the three monetary economies analyzed here. Suppose the disutility cost for a producer in the day is given by $f(x, s)=\frac{\phi x}{A} \cdot{ }^{8}$ For the case with competitive markets, we have $\Phi(x, s) \equiv \frac{\phi x}{A}$ and $\Omega(x, s) \equiv$ $\eta x\left(u_{x}-\frac{\phi}{A}\right)$. With financial frictions we have $\Phi(x, s) \equiv \frac{\eta \phi x}{A}$ and $\Omega(x, s) \equiv \eta x\left(u_{x}-\frac{\phi}{A}\right)$. With trading frictions we have $\Phi(x, s) \equiv(1-\theta) u(x)+\frac{\phi x}{A}$ and $\Omega(x, s) \equiv \frac{\Phi(x, s)\left(u_{x}-\Phi_{x}\right)}{2 \Phi_{x}}$. Note that all these functions depend on $A$ but not $\psi$, since preferences are separable in the public good.

\subsection{Calibration}

As a reference, Table 6 shows a summary of the time-series properties at annual frequencies of selected policy variables for the U.S. between 1962 and 2006. The table includes the variable $d$ GDP, which is linearly-detrended (log) real GDP.

Table 6: Time-series properties of U.S. economy — 1962-2006

\begin{tabular}{|l|c|c|c|}
\hline Variable & Mean & Std.Dev. & Autocorr. \\
\hline Debt/GDP & 0.308 & 0.078 & 0.967 \\
Inflation & 0.044 & 0.030 & 0.747 \\
Revenue/GDP & 0.182 & 0.010 & 0.653 \\
Outlays/GDP & 0.182 & 0.012 & 0.798 \\
Deficit/GDP & 0.001 & 0.018 & 0.743 \\
$d$ GDP & 0.000 & 0.027 & 0.715 \\
\hline
\end{tabular}

I keep the benchmark calibration from the previous section and assume the following:

$$
\begin{aligned}
\psi^{\prime} & =1-\varrho_{g}+\varrho_{g} \psi+\epsilon_{g}^{\prime} \\
\ln A^{\prime} & =\varrho_{A} \ln A+\epsilon_{A}^{\prime},
\end{aligned}
$$

\footnotetext{
${ }^{8}$ To derive the day-utility cost, assume a production function $x=A e$ and linear disutility in effort, $-\phi e$.
} 
where $\varrho_{g}, \varrho_{A} \in(0,1), \epsilon_{g} \sim N\left(0, \sigma_{g}^{2}\right)$ and $\epsilon_{A} \sim N\left(0, \sigma_{A}^{2}\right)$. Note that both $\psi$ and $A$ average 1 , as in the economies without aggregate uncertainty. The model is solved globally using a projection method. See Appendix D for a description of the algorithm and other details of the numerical approximation.

There are many alternative ways to calibrate or estimate the stochastic processes for $\psi$ and A. Here, I adopt an approach that allows for a single parameterization to offer empirically plausible dynamics for all three variants. Specifically, the stochastic process for $\psi$ is set to match the autocorrelation and variance of government expenditure over GDP, assuming labor productivity is constant and equal to its long-run value; the process for $A$ is set to match the autocorrelation and variance of detrended (log) real GDP (i.e., $d$ GDP), assuming the marginal value for public good consumption is fixed at its long-run value. In both cases, I target the statistics for the case with competitive markets, but the assumed processes also match the statistics for the other two cases, with only very minor deviations in the autocorrelation of expenditure and $d$ GDP. The calibrated parameters are: $\varrho_{g}=0.804, \varrho_{A}=0.726, \sigma_{g}=0.045$; $\sigma_{A}=0.061$.

\subsection{Time-series properties of artificial economies}

Artificial economies are simulated for 1,000,000 periods, starting from their respective nonstochastic steady states. Table 7 shows average, standard deviation and autocorrelation of selected policy variables. There are three different simulations for each of the three monetary economies: expenditure shocks only, productivity shocks only, and both shocks. The variable $d y$ in the model corresponds to dGDP, i.e., linearly detrended $(\log )$ real GDP. See Appendix D for a description of how it was computed.

Consider first the environment with competitive markets. Almost all of the volatility in debt and tax revenue is due to expenditure shocks, while most of the volatility in inflation is due to productivity shocks. The volatility of expenditure is similar for the two types of shocks and gets compounded when including both. The autocorrelation of these four policy variables is higher under expenditure shocks than productivity shocks, which is not surprising considering that expenditure shocks are more persistent than productivity shocks. The autocorrelation of inflation varies significantly with the type of shock, a feature which is analyzed further below. The primary deficit is slightly more volatile with productivity shocks, but the autocorrelation is nearly identical under the two types of shocks. When we consider both shocks, the volatility and autocorrelation of policy variables are reasonably close to the data, except for the autocorrelations of inflation and tax revenues - see Table 6.

Let us now compare policy across the different environments. The behavior of variables in the presence of government expenditure shocks is very similar in all cases. In contrast, the behavior of policy variables in response to productivity shocks features some important differences. Compared to the case with competitive markets, introducing financial intermediation results in slightly higher volatility in debt and inflation; the autocorrelation of inflation drops quite significantly and the autocorrelation of tax revenues increases. Incorporating trading frictions results in larger increases in the volatility of debt and inflation; the autocorrelation of inflation changes sign (becomes negative) and the autocorrelation of tax revenue increases even more. There is also a significant drop in the autocorrelation of the deficit. When we consider both types of shocks, the most significant difference across cases is the volatility and autocorrelation of inflation. For the case with trading friction, we also have a higher volatility in debt and a lower autocorrelation in the deficit. 
Table 7: Statistics for simulated economies

\begin{tabular}{|c|c|c|c|c|c|c|c|c|c|}
\hline & \multicolumn{3}{|c|}{ Competitive Markets } & \multicolumn{3}{|c|}{ Financial Intermediation } & \multicolumn{3}{|c|}{ Trading Frictions } \\
\hline & Mean & Std.Dev. & Autocorr & Mean & Std.Dev & Autocorr. & Mean & Std.Dev. & Autocorr \\
\hline \multicolumn{10}{|c|}{ Expenditure shocks } \\
\hline$\frac{B(1+\mu)}{Y}$ & 0.305 & 0.040 & 0.989 & 0.304 & 0.037 & 0.989 & 0.305 & 0.039 & 0.989 \\
\hline$\pi$ & 0.044 & 0.009 & 0.883 & 0.044 & 0.008 & 0.872 & 0.044 & 0.009 & 0.874 \\
\hline$\frac{p \tau n}{Y}$ & 0.182 & 0.007 & 0.935 & 0.182 & 0.008 & 0.928 & 0.182 & 0.007 & 0.933 \\
\hline$\frac{p g}{Y}$ & 0.182 & 0.012 & 0.798 & 0.182 & 0.012 & 0.800 & 0.182 & 0.012 & 0.797 \\
\hline$\frac{p(g-\tau n)}{Y}$ & 0.000 & 0.007 & 0.703 & 0.000 & 0.006 & 0.698 & 0.000 & 0.006 & 0.698 \\
\hline$d y$ & 0.000 & 0.013 & 0.780 & 0.000 & 0.013 & 0.775 & 0.000 & 0.013 & 0.771 \\
\hline \multicolumn{10}{|c|}{ Productivity shocks } \\
\hline$\frac{B(1+\mu)}{Y}$ & 0.310 & 0.009 & 0.921 & 0.311 & 0.018 & 0.933 & 0.310 & 0.042 & 0.942 \\
\hline$\pi$ & 0.046 & 0.031 & 0.311 & 0.046 & 0.038 & 0.079 & 0.047 & 0.057 & -0.070 \\
\hline$\frac{p \tau n}{Y}$ & 0.182 & 0.001 & 0.906 & 0.182 & 0.002 & 0.945 & 0.182 & 0.004 & 0.975 \\
\hline$\frac{p g}{Y}$ & 0.182 & 0.012 & 0.716 & 0.182 & 0.011 & 0.719 & 0.182 & 0.011 & 0.720 \\
\hline$\frac{p(g-\tau n)}{Y}$ & 0.001 & 0.011 & 0.701 & 0.001 & 0.010 & 0.681 & 0.000 & 0.009 & 0.639 \\
\hline$d y$ & 0.000 & 0.027 & 0.714 & 0.000 & 0.030 & 0.713 & 0.000 & 0.029 & 0.707 \\
\hline \multicolumn{10}{|c|}{ Both shocks } \\
\hline$\frac{B(1+\mu)}{V}$ & 0.307 & 0.041 & 0.986 & 0.307 & 0.041 & 0.978 & 0.307 & 0.057 & 0.964 \\
\hline$\pi$ & 0.046 & 0.032 & 0.355 & 0.045 & 0.039 & 0.116 & 0.046 & 0.058 & -0.047 \\
\hline$\frac{p \tau n}{Y}$ & 0.182 & 0.007 & 0.933 & 0.182 & 0.008 & 0.930 & 0.182 & 0.008 & 0.942 \\
\hline$\frac{p g}{Y}$ & 0.182 & 0.017 & 0.758 & 0.182 & 0.016 & 0.763 & 0.182 & 0.016 & 0.763 \\
\hline$\frac{p(g-\tau n)}{Y}$ & 0.001 & 0.013 & 0.702 & 0.000 & 0.012 & 0.686 & 0.000 & 0.011 & 0.662 \\
\hline$d y$ & 0.000 & 0.030 & 0.727 & 0.000 & 0.033 & 0.723 & 0.000 & 0.032 & 0.718 \\
\hline
\end{tabular}

Note: Artificial economies are simulated for 1,000,000 periods.

\subsection{Policy response to aggregate shocks}

Let us further inspect the above findings, by analyzing the response of government policy to specific shocks and comparing the results across variants. Figure 1 displays the impulse-response functions of selected variables to expenditure and aggregate shocks. The responses are computed from a VAR estimated from the simulated data; the VAR consists of the following variables (in order): $\psi, A, \frac{p(g-\tau n)}{Y}, d y, \mu$ and $\frac{B(1+\mu)}{Y}$. This VAR specification allows for an easy and precise numerical approximation to the true impulse-response functions, which cannot be accurately computed directly given that the exogenous state space is discrete. As we can see, the responses of the primary deficit, output, the money growth rate and debt are qualitatively similar in all environments. Furthermore, the three policy variables are procyclical in all cases. The main difference across monetary economies is the quantitative response of debt and monetary policy to productivity shocks. This is the source of the differences in time-series statistics across cases, as reported in Table 7 .

When a positive expenditure shock hits the economy (left panel in Figure 1), there is a persistent increase in the primary deficit. This is a standard result in any tax-smoothing model. Given that policy distortions are spread-out over time, the temporary increase in demand for night-goods by the government implies an increase in total output. Debt builds up as deficits accumulate and the effect is very persistent. The money growth rate also increases, in part to finance the extra expenditure and in part to finance the accumulated debt. These findings are consistent with the facts on post-war U.S. policy identified by Marcet and Scott (2009), most notably, the relative high persistence of debt, the persistence of deficit fluctuations and 
the positive co-movement of deficit and debt. The policy response is also consistent with the stylized facts of U.S. wartime financing - see Martin (2009) and, more recently, Martin (2011a) for more in-depth analysis.

A positive productivity shock (right panel in Figure 1) has a similar qualitative response as a positive expenditure shock. When productivity increases, agents incur in a lower disutility to produce output. Thus, policy distortions are low when productivity is temporarily high. This leads the government to increase the supply of public goods, taxes, and the money growth rate. The increase in expenditure is larger than in taxes, which results in higher deficits. Again, debt is accumulated as deficits persist. How much debt is accumulated and how fast it is repaid depends critically on the response of the money growth rate and inflation, as analyzed below. The policy response in this case is also broadly consistent with the findings in Marcet and Scott (2009) enumerated above. However, it is not consistent with their identified fact that positive innovations to GDP are followed by reductions in debt and deficits (instead of increases as in Figure 1), at least as long as one interprets innovations to output as shocks to productivity. In the model, tax revenue increases during a boom, as in the data, but the response is too mild, which leads to the counterfactual implication for deficits. ${ }^{9}$

In all three model variants, the response of inflation to a productivity shock has an important difference with the response of the money growth rate. To see this, note that prices for the case with competitive markets are $\tilde{p}=\frac{1}{x}$ and $p=\frac{A U_{c}}{\phi x}$ in the day and night markets, respectively; taxes are $\tau=1-\frac{\alpha}{A U_{c}}$. As reported in Table 7 , the volatility of taxes in the presence of productivity shocks is very small; thus, the volatility of $A U_{c}$ is close to zero. When a positive innovation to $A$ hits the economy, $x$ increases, $A U_{c}$ remains approximately the same and so, both $\tilde{p}$ and $p$ decrease. This behavior is displayed despite the fact that $\mu$ actually increases in response to a positive innovation in $A$, as shown in Figure 1. In the subsequent periods after the shock, prices increase at a decreasing rate; i.e., after the initial period, inflation follows the behavior of the money growth rate. Thus, most of the difference in the autocorrelation of inflation between monetary economies is due to how large the initial drop in prices is. This is a feature of the underlying monetary framework and not of the government policy model.

The case with trading frictions presents an interesting oddity. The response of monetary policy to a productivity shocks is the smoothest of all cases, while the volatility of inflation is the highest. Most of the volatility in inflation reported for the environment with trading frictions does not stem from variations in the money supply, but from changes in the money demand, which in turn reacts to both the aggregate shocks and the endogenous policy response.

\subsection{Policy persistence}

To better measure the persistence of policy variables, Marcet and Scott (2009) suggest using the k-variance ratio, which is defined as $P_{x}^{k}=\frac{\operatorname{Var}\left(x_{t}-x_{t-k}\right)}{k \operatorname{Var}\left(x_{t}-x_{t-1}\right)}$. A variable is more persistent the longer it takes the k-variance ratio to converge to zero. Figure 2 compares the persistence of debt, inflation and the deficit, in the data and artificial economies.

In the data, the k-variance ratio for debt over GDP is increasing and only starts leveling off after 9 years at about 3.7. Inflation and the deficit are much less persistent and both series display a more or less decreasing $P^{k}$ ratio. Furthermore, the persistence in inflation and the

\footnotetext{
${ }^{9}$ Marcet and Scott (2009) show that a Ramsey model of optimal taxation, exogenous expenditure and incomplete markets displays decreasing deficits and debt in response to a positive productivity shock. However, note that with commitment, tax rates are essentially constant over the business cycle, so the result follows mechanically from the increase in output. Thus, although the response of the primary deficit is consistent with the U.S. data, the behavior of taxes is not. Their model also abstracts from monetary policy, which would render it a complete markets environment and therefore nullify all the good predictions. See Chari et al. (1991) and Aruoba and Chugh (2008) for simulations of economies with commitment and joint fiscal and monetary policy.
} 
deficit are relatively similar. As we can see in Figure 2, all model variants match these qualitative features broadly. The $P^{k}$ ratios for inflation and the deficit are quite close to the data in all cases, especially after a few periods. The big difference between variants is in the persistence of debt. The case with competitive markets provides the best fit to the data, whereas the other two cases match the qualitative shape of debt persistence, but underestimate it quantitatively.

\subsection{Money demand}

Let us evaluate the model's implication for the money demand, i.e., the relationship between the nominal interest rate and the inverse of velocity of circulation. Note that neither of these variables were calibration targets. For the U.S. data, define velocity of money as nominal GDP divided by average $M_{1}$, which is the measure typically adopted by the literature. For the interest rate, I use the 1-year treasury constant maturity rate published by the Federal Reserve, which is closely related to the nominal interest rate in the model. One issue with the data is that velocity of circulation has a secular trend whereas the interest rate does not. To remove this effect, I linearly detrend the series for the inverse of velocity. In the model, velocity of circulation is defined as (normalized) nominal aggregate output, $Y$, and the interest rate is $i=1 / q-1$.

Consider the money demand regression $d k_{t}=\gamma d i_{t}+\varepsilon_{t}$, where $d k$ and $d i$ are deviations from mean of the (detrended) inverse of velocity and the nominal interest rate, respectively. Table 8 reports the results of the money demand regressions in the data and the model. For the artificial economies, the demand equation is estimated using the simulated sample of 1,000,000 periods. This method provides an estimate of the "true" relationship between $k$ and $i$ in the model. Fit can be evaluated by checking whether the model estimate for $\gamma$ falls within the one-standard error band in the data. Figure 3 complements the analysis with a graphical representation of the money demand curve in the data and the initial 10,000 simulation periods in each monetary economy.

Table 8: Money demand regression: $d k_{t}=\gamma d i_{t}+\varepsilon_{t}$

\begin{tabular}{|l|c|c|c|c|}
\hline & $\begin{array}{c}\text { U.S. Data } \\
1962-2006\end{array}$ & $\begin{array}{c}\text { Competitive } \\
\text { Markets }\end{array}$ & $\begin{array}{c}\text { Financial } \\
\text { Intermediation }\end{array}$ & $\begin{array}{c}\text { Trading } \\
\text { Frictions }\end{array}$ \\
\hline$\gamma$ & -0.442 & -0.432 & -0.394 & -0.105 \\
& $(0.057)$ & $(0.000)$ & $(0.000)$ & $(0.001)$ \\
$R^{2}$ & 0.583 & 0.707 & 0.644 & 0.024 \\
\hline
\end{tabular}

Note: Standard errors are shown in parenthesis.

As we can see in Table 8, all cases feature a money demand curve with a negative slope. The model fit is very good for the cases with competitive markets and financial intermediation. The case with trading frictions features a poor fit, which as can be observed in Figure 3, is due to the relatively high volatility of the money demand - see Section 5.4 for a related discussion.

\subsection{Phillips curve}

Lastly, we compare the model variants by studying the implied relationship between inflation and output, i.e., a variant of the standard Phillips curve. For the U.S. annual data between 1962 and 2006, the regression $d \pi_{t}=\gamma d y_{t}+\varepsilon_{t}$ implies $\gamma=0.521$, with a standard error of 0.150 . Table 9 displays the Phillips curve regression for the U.S. data and simulated economies. Figure 4 provides a graphical representation. 
Table 9: Phillips curve regression: $d \pi_{t}=\gamma d y_{t}+\varepsilon_{t}$

\begin{tabular}{|l|c|c|c|c|}
\hline & $\begin{array}{c}\text { U.S. Data } \\
\text { 1962-2006 }\end{array}$ & $\begin{array}{c}\text { Competitive } \\
\text { Markets }\end{array}$ & $\begin{array}{c}\text { Financial } \\
\text { Intermediation }\end{array}$ & $\begin{array}{c}\text { Trading } \\
\text { Frictions }\end{array}$ \\
\hline$\gamma$ & 0.521 & 0.400 & 0.152 & -0.275 \\
& $(0.150)$ & $(0.001)$ & $(0.001)$ & $(0.002)$ \\
$R^{2}$ & 0.219 & 0.141 & 0.016 & 0.023 \\
\hline
\end{tabular}

Note: Standard errors are shown in parenthesis.

The case with competitive markets implies an estimated coefficient on $d y_{t}$ of 0.400 , which falls within the one standard error band of the data estimate. The positive correlation between inflation and GDP in the model obtains despite a negative policy trade-off between the two variables (since inflation is distortionary), and results from the interaction between policy and aggregate shocks over time. Figure 4 displays very clearly how locally negative policy trade-offs shift around with aggregate shocks, so that the long-run relationship becomes positive.

For the case with financial intermediation, the coefficient in the Phillips curve regression is also positive, but significantly lower than with competitive markets. For the case with trading frictions, the coefficient is actually negative. In both these variants, the $R^{2}$ is close to zero, i.e., real GDP has virtually no explanatory power for inflation. This result is also apparent from Figure 4.

The differences between economies follow from the behavior of inflation in the presence of productivity shocks - see Table 7 . To smooth out any artifacts generated by the contemporaneous response of inflation, I run the regressions using 5-year moving averages. ${ }^{10}$ Table 10 shows that all variants now feature a positively-sloped Phillips curve, although the case with competitive markets still offers the closest fit to the data. Also note that the $R^{2}$ for all cases is significantly higher than in Table 9 .

Table 10: Phillips curve regression: $d \pi_{t}=\gamma d y_{t}+\varepsilon_{t}$, using 5-year moving averages

\begin{tabular}{|l|c|c|c|c|}
\hline & $\begin{array}{c}\text { U.S. Data } \\
1962-2006\end{array}$ & $\begin{array}{c}\text { Competitive } \\
\text { Markets }\end{array}$ & $\begin{array}{c}\text { Financial } \\
\text { Intermediation }\end{array}$ & $\begin{array}{c}\text { Trading } \\
\text { Frictions }\end{array}$ \\
\hline$\gamma$ & 0.703 & 0.704 & 0.529 & 0.299 \\
& $(0.236)$ & $(0.002)$ & $(0.002)$ & $(0.003)$ \\
$R^{2}$ & 0.186 & 0.657 & 0.444 & 0.098 \\
\hline
\end{tabular}

Note: Standard errors are shown in parenthesis.

\subsection{Robustness}

A legitimate concern is that the preceding analysis may be sensitive to the calibration adopted in Section 3. In particular, the values of $\eta$ and $\bar{x}$ where chosen arbitrarily. In this section, I will verify the robustness of the results obtained above, by focusing on three key elements: (i) the time-series statistics in Table 7 with both shocks; (ii) the k-variance ratio for debt; and (iii) the money demand and Phillips curve regressions. ${ }^{11}$

\footnotetext{
${ }^{10} \mathrm{I}$ also conducted a similar exercise for the money demand regressions, but found no significant differences with the results presented in Table 8 .

${ }^{11}$ To keep this section brief, I only report the results of the exercise. All supporting computations are available upon request.
} 
First, let us analyze how the cases with competitive markets and financial intermediation are affected by changes in the measure of buyers, $\eta$. Lowering $\eta$ for the case with competitive markets improves the model fit. For example, set $\eta=0.3$ and recalibrate to match the target statistics. Then, we get the following improvements: standard deviation of debt increases to 0.043; standard deviation of inflation decreases to 0.030; autocorrelation of inflation increases to 0.487 ; k-variance ratio for debt increases for all periods (after 10 periods it is equal to 3.84); and $\gamma$ coefficient in the Phillips curve regression equal to 0.491. The other statistics do not change significantly, except for a lower coefficient in the money demand regression, -0.412 . On the other hand, varying $\eta$ (and recalibrating) for the case with financial intermediation has no significant effect on any the variables considered here; all statistics for the simulated economy look virtually identical for different values of $\eta$.

Second, consider the effects of the parameter $\bar{x}$ in the utility function for the day-good, $u(x)$. The calibration specifies $\bar{x}=0$ for the case with competitive markets and $\bar{x}=0.500$ for the case with trading frictions. Assume $\bar{x}=0.500$ for the case with competitive markets and recalibrate parameters to match target statistics. Then, the results are virtually identical to those of the benchmark calibration. Suppose instead that we set $\bar{x}=0.005$ for the case with trading frictions and recalibrate. Here, there are a few noticeable changes, but not significant enough to overturn any of the reported conclusions.

Third, since the reason why the economy with trading frictions does not fit the data as well as the other cases is the behavior of the money demand, consider lowering the size of the bargaining frictions by reducing the targeted markup by half. In this case the fit improves significantly. We get: lower volatility and higher persistence of inflation (the standard deviation falls to 0.048 and the autocorrelation increases to 0.010 ), although the volatility of debt falls (standard deviation decreases to 0.051); increased persistence of debt, as measured by the k-variance ratio (about 15\% higher than benchmark after 6 periods); closer estimates for the money demand and Phillips curve regressions $(-0.242$ and -0.052 , respectively). Overall, lowering trading frictions improves model fit, but the economies with competitive markets and financial intermediation still outperform.

\section{Concluding remarks}

The results in the preceding sections contribute to two separate strands of the macroeconomic literature. First, the analysis complements studies in monetary theory by providing a theoretical treatment of how environment frictions affect the (endogenous) determination of government policy. It also proposes a method for testing alternative variants of monetary economies by evaluating their performance relative to the data along several relevant dimensions. Second, the paper advances our understanding of government policy (both normative and positive) by identifying which results depend on the specific details of micro founded monetary economies and which findings remain unaltered.

\section{References}

Aiyagari, S. R. and McGrattan, E. R. (1998), 'The optimum quantity of debt', Journal of Monetary Economics 42(3), 447-469.

Alvarez, F., Kehoe, P. J. and Neumeyer, P. A. (2004), 'The time consistency of optimal monetary and fiscal policies', Econometrica $\mathbf{7 2}(2), 541-567$.

Aruoba, S. B. and Chugh, S. K. (2008), Optimal fiscal and monetary policy when money is essential. Mimeo. 
Aruoba, S. B. and Chugh, S. K. (2010), 'Optimal fiscal and monetary policy when money is essential', Journal of Economic Theory 145(5), 1618-1647.

Aruoba, S. B., Rocheteau, G. and Waller, C. (2007), 'Bargaining and the value of money', Journal of Monetary Economics 54, 2636-2655.

Aruoba, S. B., Waller, C. and Wright, R. (2011), 'Money and capital', Journal of Monetary Economics 58(2).

Azzimonti, M., Sarte, P.-D. and Soares, J. (2009), 'Distortionary taxes and public investment when government promises are not enforceable', Journal of Economic Dynamics and Control 33(9), 1662-1681.

Barro, R. J. (1979), 'On the determination of the public debt', The Journal of Political Economy 87(5), 940-971.

Barseghyan, L., Battaglini, M. and Coate, S. (2010), Fiscal policy over the real business cycle: A positive theory. Mimeo.

Battaglini, M. and Coate, S. (2008), 'A dynamic theory of public spending, taxation and debt', American Economic Review 98(1), 201-236.

Berentsen, A., Camera, G. and Waller, C. (2007), 'Money, credit and banking', Journal of Economic Theory 135, 171-195.

Berentsen, A. and Waller, C. (2008), 'Outside versus inside bonds', Working Paper No. 372, Institute for Empirical Research in Economics, University of Zurich .

Chari, V. V., Christiano, L. J. and Kehoe, P. J. (1991), 'Optimal fiscal and monetary policy: Some recent results', Journal of Money, Credit and Banking 23(3), 519-539.

Diamond, P. A. (1965), 'National debt in a neoclassical growth model', American Economic Review 55(5), 1126-1150.

Díaz-Giménez, J., Giovannetti, G., Marimón, R. and Teles, P. (2008), 'Nominal debt as a burden on monetary policy', Review of Economic Dynamics 11(3), 493-514.

Flodén, M. (2008), 'A note on the accuracy of Markov-chain approximations to highly persistent AR(1) processes', Economic Letters 99, 516-520.

Gomis-Porqueras, P. and Peralta-Alva, A. (2009), 'Optimal monetary and fiscal policies in a search theoretic model of monetary exchange', European Economic Review .

Kalai, E. (1977), 'Proportional solutions to bargaining situations: Interpersonal utility comparisons', Econometrica 45, 1623-1630.

Klein, P., Krusell, P. and Ríos-Rull, J.-V. (2008), 'Time-consistent public policy', The Review of Economic Studies 75(3), 789-808.

Kocherlakota, N. (1998), 'Money is memory', Journal of Economic Theory 81, 232-251.

Krusell, P. and Smith, A. (2003), 'Consumption-savings decisions with quasi-geometric discounting', Econometrica 71(1), 365-375.

Lagos, R. and Wright, R. (2005), 'A unified framework for monetary theory and policy analysis', The Journal of Political Economy 113(3), 463-484.

Lucas, R. E. (1986), 'Principles of fiscal and monetary policy', Journal of Monetary Economics 17, 117-134. 
Lucas, R. E. and Stokey, N. L. (1983), 'Optimal fiscal and monetary policy in an economy without capital', Journal of Monetary Economics 12(1), 55-93.

Marcet, A. and Scott, A. (2009), 'Debt and deficit fluctuations and the structure of bond markets', Journal of Economic Theory 144, 473-501.

Martin, F. M. (2009), 'A positive theory of government debt', Review of Economic Dynamics $\mathbf{1 2}(4), 608-631$.

Martin, F. M. (2010), 'Markov-perfect capital and labor taxes', Journal of Economic Dynamics and Control 34(3), 503-521.

Martin, F. M. (2011a), Government policy response to war-expenditure shocks. Mimeo.

Martin, F. M. (2011b), 'On the joint determination of fiscal and monetary policy', Journal of Monetary Economics 58(2), 132-145.

Maskin, E. and Tirole, J. (2001), 'Markov perfect equilibrium', Journal of Economic Theory 100(2), 191-219.

Nash, J. (1950), 'The bargaining problem', Econometrica 18, 155-162.

Niemann, S. (2011), 'Dynamic monetary-fiscal interactions and the role of monetary conservatism', Journal of Monetary Economics, forthcoming .

Niemann, S., Pichler, P. and Sorger, G. (2009), Inflation dynamics under optimal discretionary fiscal and monetary policies. Economics Discussion Papers, University of Essex.

Ohanian, L. E. (1998), The Macroeconomic Effects of War Finance in the United States: Taxes, Inflation, and Deficit Finance, Routledge.

Ortigueira, S. (2006), 'Markov-perfect optimal taxation', Review of Economic Dynamics 9, 153178.

Sargent, T. and Wallace, N. (1981), 'Some unpleasant monetarist arithmetic', Minneapolis Federal Reserve Bank Quarterly Review, Fall .

Shi, S. (2006), 'Viewpoint: A microfoundation of monetary economics', Canadian Journal of Economics 39(3), 643-688.

Shin, Y. (2006), Ramsey meets Bewley: Optimal government financing with incomplete markets. Mimeo.

Tauchen, G. (1986), 'Finite state markov-chain approximations to univariate and vector autoregressions', Economics Letters 20, 177-181.

Wallace, N. (1998), 'A dictum for monetary theory', Federal Reserve Bank of Minneapolis Quarterly Review 22(1), 20-26.

Wallace, N. (2001), 'Whither monetary economics?', International Economic Review 42(4), 847869.

Williamson, S. and Wright, R. (2010), New monetarist economics: Models, in B. M. Friedman and M. Woodford, eds, 'Handbook of Monetary Economics', Vol. 3, North Holland, Amsterdam. 


\section{Appendix}

\section{A Proofs}

\section{A.1 Lemma 1}

(i) Follows from Assumption 1.

(ii) Since bonds are not used in the day, they do not affect the agent's day problem. Thus, starting the day with an extra unit of bonds, implies starting the night with an extra unit of bonds, i.e., $V_{b}=W_{z}$. The result follows from $\Phi(x)=W_{z}$ by Assumption 1 .

(iii) For money to be valued in equilibrium, it needs to provide a liquidity service in the day market. Thus, $V_{m}-W_{z} \geq 0$ and so $\Omega(x) \geq 0$.

(iv) By (iii) $x \leq \hat{x}$ in a monetary equilibrium. If $x<\hat{x}$ then $V_{m}>W_{z}$, i.e., the value of money is too high, which means consumers are cash-constrained. If $x=\hat{x}$ then $V_{m}=W_{z}$ and consumers spend all their cash without any loss of generality.

\section{A.2 Proposition 1}

We will use the following auxiliary lemma.

Lemma $2 \lambda=0$ if and only if $\{\hat{x}, \hat{c}, \hat{g}\}$ is implemented in all periods.

Proof. Suppose $\lambda=0$. Then, from (14) we get $x=\hat{x}, \Omega_{x}(\hat{x})<0$ and thus, $u_{x}-f_{\kappa}=\zeta=0$ is the only solution. From (15) and (16), we get $c=\hat{c}$ and $g=\hat{g}$. From (13), we get $\Lambda\left(B^{\prime}\right)=0$, which from (14)-(16) implies $x^{\prime}=\hat{x}, c^{\prime}=\hat{c}$ and $g^{\prime}=\hat{g}$. Suppose now that $x=x^{\prime}=\hat{x}$, $c=c^{\prime}=\hat{c}$ and $g=\hat{g}$. Then, equations (14)-(16) all imply $\lambda=0$.

(i) Suppose not, i.e., $\Lambda(B)=0$ for some $B \in \Gamma$. Then, (14) becomes $\eta\left(u_{x}-f_{\kappa}\right)+\zeta \Omega_{x}=0$, which implies $\mathcal{X}(B)=\hat{x}$. From (15) and $(16)$ we get $\mathcal{C}(B)=\hat{c}$ and $\mathcal{G}(B)=\hat{g}$. From (12), $\mathcal{B}(B)=\frac{\alpha \hat{g}}{\beta \Phi(\hat{x})}+\frac{1+B}{\beta}-1>B$. By Lemma 2, the first-best allocation $\{\hat{x}, \hat{c}, \hat{g}\}$ is also implemented in all future periods. Thus, the policy from the current period on is $\hat{\mu}=\beta-1, \hat{\tau}=0, \hat{q}=1$ and $\hat{p}=\frac{\alpha}{\Phi(\hat{x})}$; the value function is $\mathcal{V}(B)=\hat{V} \equiv \frac{\eta u(\hat{x})+(1-\eta) f(\hat{\kappa})+U(\hat{c})-\alpha(\hat{c}+\hat{g})+v(\hat{g})}{1-\beta}$.

By Lemma 1(iv), consumers spend all their money in the day. Depending on the specific structure of the day-market, consumers may be able to borrow some of the money brought by producers. Given that in equilibrium all agents starts the day with $m=1$, the most a consumer will be able to borrow from producers in any day-market specification is $\frac{1-\eta}{\eta}$. Since we are at the first-best, the financial cost of these loans is zero-note that $\hat{q}=1$, i.e., the nominal interest rate $\frac{1}{\hat{q}}-1$ is zero. Thus, a consumer arrives at the night market with net nominal balances equal to $B-\Delta$, where $\Delta \in\left[0, \frac{1-\eta}{\eta}\right]$, and works $\hat{n}^{c}=\frac{\hat{c}}{1-\hat{\tau}}-\frac{B-\Delta-(1+\hat{\mu})\left(m^{\prime}+\hat{q} b^{\prime}\right)}{\hat{p}(1-\hat{\tau})}=\hat{c}-\frac{\Phi(\hat{x})\left(B-\Delta-\beta\left(m^{\prime}+b^{\prime}\right)\right)}{\alpha}$. If he does not deviate, he chooses $m^{\prime}=1$ and $b^{\prime}=\mathcal{B}(B)$ and hence works $\hat{n}^{c}=\hat{c}+\hat{g}+\frac{\Phi(\hat{x})(1+\Delta)}{\alpha}$. Thus, the equilibrium pay-off for a consumer at night is $\hat{W}^{c}=U(\hat{c})-\alpha(\hat{c}+\hat{g})-\Phi(\hat{x})(1+\Delta)+$ $v(\hat{g})+\beta \hat{V}$.

Consider now a consumer that deviates at night in the following way: he still consumes $\hat{c}$ and chooses $m^{\prime}=1$, but now he sells all his bonds, i.e., $b^{\prime}=0$ and saves on work accordingly. After the current period, the agent maintains a portfolio of zero bonds and finances his (firstbest) consumption with fiat money and labor only. Thus, in future periods the agent works $n_{d}=\hat{c}+\frac{\Phi(\hat{x})(\beta-z)}{\alpha}$. Expected nominal balances $z$ are equal to 1, regardless of whether there is 
money intermediation in the day-market or not, and thus expected night-labor is $\hat{c}-\frac{\Phi(\hat{x})(1-\beta)}{\alpha}$. The value of this continuation strategy is then $V_{d}=\frac{\eta u(\hat{x})+(1-\eta) f(\hat{\kappa})+U(\hat{c})-\alpha \hat{c}+\Phi(\hat{x})(1-\beta)+v(\hat{g})}{1-\beta}$. In the deviation period, the consumer chooses $c=\hat{c}, m^{\prime}=1$ and $b^{\prime}=0$ and thus, works $n_{d}^{c}=$ $\hat{c}+\frac{\Phi(\hat{x})(\beta-B+\Delta)}{\alpha}$. The pay-off from deviating is $W_{d}^{c}=U(\hat{c})-\alpha \hat{c}-\Phi(\hat{x})(\beta-B+\Delta)+v(\hat{g})+\beta V_{d}$. A consumer has an incentive to deviate only if $W_{d}^{c}>\hat{W}^{c}$. After some simple algebra, this condition reduces to $B>\hat{B} \equiv-1-\frac{\alpha \hat{g}}{(1-\beta) \Phi(\hat{x})}$. Thus, there is a profitable deviation from the equilibrium for any $B \in \Gamma$, a contradiction with $\Lambda(B)=0$ for some $B \in \Gamma$.

(ii) Given $\lambda \Phi_{x}(1+B) \geq 0$, (14) implies $\eta\left(u_{x}-f_{\kappa}\right)+\zeta \Omega_{x} \geq 0$. Suppose $\eta\left(u_{x}-f_{\kappa}\right)+\zeta \Omega_{x}=0$. Given $\Omega_{x}(\hat{x})<0$ by Assumption 1 , the only solution is $x=\hat{x}$. Suppose now $\eta\left(u_{x}-f_{\kappa}\right)+\zeta \Omega_{x}>0$. Given $\zeta \Omega_{x}(\hat{x}) \leq 0$, the solution is $x<\hat{x}$ and $\zeta=0$.

(iii) Suppose not, i.e., $\mathcal{X}_{B} \geq 0$ for some $B \in \Gamma$. Totally differentiating (14) we get:

$$
\left\{\eta\left(u_{x x}-\frac{\eta f_{\kappa \kappa}}{1-\eta}\right)-\lambda \Phi_{x x}(1+B)\right\} \mathcal{X}_{B}=\Lambda_{B} \Phi_{x}(1+B)+\lambda \Phi_{x} .
$$

Given $u_{x x}<0, f_{\kappa \kappa} \geq 0, \lambda>0, \Phi_{x x}(1+B) \geq 0$ and $\mathcal{X}_{B} \geq 0$, the left-hand side of the expression above is weakly negative. Since $\Phi_{x}>0$, we get a contradiction for $B=-1$ and $\Lambda_{B}<0$ for $B>-1$.

From (16), $\Lambda_{B}<0$ implies $\mathcal{G}_{B}>0$. From (15) and (16) we get $F(c, g) \equiv v_{g}\left(U_{c}-\alpha\right)+\left(v_{g}-\right.$ $\alpha) U_{c c} c=0$. By the Implicit Function Theorem, $\frac{d c}{d g}=-\frac{F_{g}}{F_{c}}$. We get $F_{g}=v_{g g}\left(U_{c}-\alpha+U_{c c} c\right)>0$, since from (15), $\lambda>0$ implies $U_{c}-\alpha+U_{c c} c<0$. Thus, to show $\frac{d c}{d g}>0$ and thus, $\mathcal{C}_{B}>0$, we need $F_{c}<0$. We get $F_{c}=v_{g} U_{c c}+\left(v_{g}-\alpha\right)\left(U_{c c}+U_{c c c} c\right)$, which using $F(c, g)=0$ can be rewritten as $F_{c}=\frac{v_{g}}{c}\left\{U_{c c} c-\left(U_{c}-\alpha\right)\left(1+\frac{U_{c c c} c}{U_{c c}}\right)\right\}$; by assumption, this expression is negative, which implies $\mathcal{C}_{B}>0$.

Given the above results, starting the period with a higher $B$ results in: (weakly) higher $x$ since $\mathcal{X}_{B} \geq 0$; higher $c$ and $g$ since $\mathcal{C}_{B}>0$ and $\mathcal{G}_{B}>0$; and a more relaxed budget constraint since $\Lambda_{B}>0$. This implies the government could increase welfare with an infinitesimal increase in debt, which contradicts $\mathcal{V}_{B}=-\lambda \Phi(x)<0$.

(iv) By (14) and part (ii), $\mathcal{X}(-1)=\hat{x}$; by part (iii) $\mathcal{X}(B)<\hat{x}$ for all $B>-1$.

Suppose $\mathcal{B}(B)=-1$ for some $B \in \Gamma$. Then (13) becomes $\Phi(\hat{x})[\lambda-\Lambda(-1)]+\lambda \mathcal{X}_{B}^{\prime} \Omega_{x}^{\prime}=0$. Since $\lambda \mathcal{X}_{B}^{\prime} \Omega_{x}^{\prime}>0$ by parts (i) and (iii) and Assumption $1, \lambda-\Lambda(-1)<0$. This last result holds regardless of whether the solution is interior or a corner. $\lambda<\Lambda(-1)$ rules out $B=-1$; hence, $\mathcal{B}(-1)>-1$. Next, focus on $B>-1$. Evaluating (12) today and tomorrow we get:

$$
\begin{aligned}
\left(U_{c}-\alpha\right) c-\alpha g-\Phi(x)(1+B) & =0 \\
\left(U_{c}^{\prime}-\alpha\right) c^{\prime}-\alpha g^{\prime}+\beta \Omega(\mathcal{X}(\mathcal{B}(-1)))+\beta \Phi(\mathcal{X}(\mathcal{B}(-1)))[1+\mathcal{B}(-1)] & =0 .
\end{aligned}
$$

Since $B>-1$, we get $\left(U_{c}-\alpha\right) c-\alpha g>0$; since $\mathcal{B}(-1)>-1$ and $\mathcal{X}(\mathcal{B}(-1))<\hat{x}$ we get $\left(U_{c}^{\prime}-\alpha\right) c^{\prime}-\alpha g^{\prime}<0$. By the argument in part (iii) we know that $\frac{d c}{d g}>0$. Also note that $\left(U_{c}-\alpha\right) c$ is strictly decreasing in $c$ since from (15), $\lambda>0$ implies $U_{c}-\alpha+U_{c c} c<0$. Thus, $c<c^{\prime}$ and $g<g^{\prime}$. From (16) this implies $\lambda>\Lambda(-1)$, a contradiction.

Given $B^{\prime}>-1, x^{\prime}<\hat{x}$ and so from $(11) q<1$.

\section{A.3 Proposition 2}

Follows from (17), given $\Phi_{x}^{*}>0$ by Assumption 1. 


\section{A.4 Proposition 3}

Consider the government problem with commitment, also known as the Ramsey problem. A standard result is that the sequence of government budget constraints collapses to a single "implementability" constraint. Start with (1). For every period, multiply this equation by $\frac{\beta^{t} U_{c, t}}{p_{t}}$ and sum over all periods. We get:

$$
\sum_{t=0}^{\infty} \beta^{t} U_{c, t}\left\{\tau_{t} c_{t}-\left(1-\tau_{t}\right) g_{t}+\frac{\left(1+\mu_{t}\right)\left(1+q_{t} B_{t+1}\right)-\left(1+B_{t}\right)}{p_{t}}\right\}=0
$$

Using (9) and the transversality condition, $\lim _{T \rightarrow \infty} \beta^{T} \frac{\left(1+\mu_{T}\right)\left(1+q_{T} B_{T+1}\right)}{p_{T}}=0$, the expression above simplifies to

$$
\sum_{t=0}^{\infty} \beta^{t}\left\{\left(U_{c, t}-\alpha\right) c_{t}-\alpha g_{t}\right\}-\frac{U_{c, 0}\left(1+B_{0}\right)}{p_{0}}+\sum_{t=1}^{\infty} \beta^{t-1}\left\{\frac{U_{c, t-1}\left(1+\mu_{t-1}\right)\left(1+q_{t-1} B_{t}\right)}{p_{t-1}}-\frac{\beta U_{c, t}\left(1+B_{t}\right)}{p_{t}}\right\}=0 .
$$

The remaining step is to show that the whole third term can be simplified to an expression that only depends on $\left\{x_{t}\right\}_{t=0}^{\infty}$. We can rewrite this term as

$$
\sum_{t=1}^{\infty} \beta^{t-1}\left\{\frac{U_{c, t-1}\left(1+\mu_{t-1}\right)}{p_{t-1}}-\frac{\beta U_{c, t}}{p_{t}}+\left(\frac{U_{c, t-1}\left(1+\mu_{t-1}\right) q_{t-1}}{p_{t-1}}-\frac{\beta U_{c, t}}{p_{t}}\right) B_{t}\right\}
$$

Using (8), (10) and (11), we can show that $\frac{U_{c, t-1}\left(1+\mu_{t-1}\right) q_{t-1}}{p_{t-1}}-\frac{\beta U_{c, t}}{p_{t}}=0$. The term $\frac{U_{c, t-1}\left(1+\mu_{t-1}\right)}{p_{t-1}}-$ $\frac{\beta U_{c, t}}{p_{t}}$ simplifies to $\beta \Omega\left(x_{t}\right)$. Thus, the implementability constraint is

$$
\sum_{t=0}^{\infty} \beta^{t}\left\{\left(U_{c, t}-\alpha\right) c_{t}-\alpha g_{t}+\Omega\left(x_{t}\right)\right\}-\Omega\left(x_{0}\right)-\left(1+B_{0}\right) \Phi\left(x_{0}\right)=0
$$

Given $B_{0} \geq-1$, the problem of the government is

$$
\max _{\left\{x_{t}, c_{t}, g_{t}\right\}_{t=0}^{\infty}} \sum_{t=0}^{\infty} \beta^{t}\left\{\eta u\left(x_{t}\right)-(1-\eta) f\left(\kappa_{t}\right)+U\left(c_{t}\right)-\alpha\left(c_{t}+g_{t}\right)+v\left(g_{t}\right)\right\}
$$

subject to (25) and where $\kappa_{t}=\frac{\eta x_{t}}{1-\eta}$. It is easy to verify that the non-negativity constraint, $\Omega\left(x_{t}\right) \geq 0$, does not bind in any period. The first-order conditions are

$$
\begin{aligned}
& \eta\left(u_{x, 0}-f_{\kappa, 0}\right)-\lambda\left(1+B_{0}\right) \Phi_{x, 0}=0, \quad \text { for } t=0 \\
& \eta\left(u_{x, t}-f_{\kappa, t}\right)+\lambda \Omega_{x, t}=0, \quad \text { for all } t \geq 1 \\
& U_{c, t}-\alpha+\lambda\left(U_{c, t}-\alpha+U_{c c, t} c_{t}\right)=0, \quad \text { for all } t \geq 0 \\
& v_{g, t}-\alpha-\lambda \alpha=0, \quad \text { for all } t \geq 0,
\end{aligned}
$$

where $\lambda$ is the Lagrange multiplier associated with (25). Note that $c_{t}$ and $g_{t}$ are constant for all $t \geq 0$, while $x_{t}$ is constant for all $t \geq 1$ and may be different in the initial period. Call the corresponding allocation $\left\{x_{0}, x_{1}, c, g\right\}$. Thus, we can write $(25)$ as $\left(U_{c}-\alpha\right) c-\alpha g+\beta \Omega\left(x_{1}\right)=$ $(1-\beta) \Phi\left(x_{0}\right)\left(1+B_{0}\right)$. Plug this expression into the period budget constraint (12) and we get $B_{t}=\frac{\Phi\left(x_{0}\right)\left(1+B_{0}\right)}{\Phi\left(x_{1}\right)}-1$ for all $t \geq 1$, i.e., debt is constant after the initial period. Thus, $\left\{x_{0}, x_{1}, c, g\right\}$ solves

$$
\begin{aligned}
\alpha \eta\left(u_{x, 0}-f_{\kappa, 0}\right)-\left(v_{g}-\alpha\right) \Phi_{x, 0}\left(1+B_{0}\right) & =0 \\
\alpha \eta\left(u_{x, 1}-f_{\kappa, t}\right)+\left(v_{g}-\alpha\right) \Omega_{x, 1} & =0 \\
v_{g}\left(U_{c}-\alpha\right)+\left(v_{g}-\alpha\right) U_{c c} c & =0 \\
\left(U_{c}-\alpha\right) c-\alpha g+\beta \Omega\left(x_{1}\right)-(1-\beta) \Phi\left(x_{0}\right)\left(1+B_{0}\right) & =0 .
\end{aligned}
$$


Suppose $B_{0}=B^{*}$. We now verify that $\left\{x^{*}, x^{*}, c^{*}, g^{*}\right\}$ solves the above system. We get

$$
\begin{aligned}
\alpha \eta\left(u_{x}^{*}-f_{\kappa}^{*}\right)-\left(v_{g}^{*}-\alpha\right) \Phi_{x}^{*}\left(1+B^{*}\right) & =0 \\
\alpha \eta\left(u_{x}^{*}-f_{\kappa}^{*}\right)+\left(v_{g}^{*}-\alpha\right) \Omega_{x}^{*} & =0 \\
v_{g}^{*}\left(U_{c}^{*}-\alpha\right)+\left(v_{g}^{*}-\alpha\right) U_{c c}^{*} c^{*} & =0 \\
\left(U_{c}^{*}-\alpha\right) c^{*}-\alpha g^{*}+\beta \Omega\left(x^{*}\right)-(1-\beta) \Phi\left(x^{*}\right)\left(1+B^{*}\right) & =0 .
\end{aligned}
$$

Equations (27) and (28) are identical to the MPME steady state conditions, (18) and (19), respectively. When plugging $1+B^{*}=\frac{\Omega_{x}^{*}}{\Phi_{x}^{*}}$ from (17), equations (26) and (29) are identical to (18) and (20), respectively. Thus, given $B_{0}=B^{*}$, the solution to the Ramsey problem is $\left\{B_{t}=B^{*}, x_{t}=x^{*}, c_{t}=c^{*}, g_{t}=g^{*}\right\}$ for all $t \geq 0$.

\section{A.5 Proposition 4}

(i) Clearly, (18)-(20) yield the same solution for $\left\{x^{*}, c^{*}, g^{*}\right\}$ for any economy that shares the same $\Omega(x)$ and $\frac{\Phi(x)}{\Phi_{x}}$. From (9) it follows that $\tau^{*}$ is also the same.

(ii) From (8), (11) and (17) we get $\mu^{*}=\frac{\beta \Omega\left(x^{*}\right)}{\Phi\left(x^{*}\right)}+\beta-1, q^{*}=\frac{1}{1+\frac{\Omega\left(x^{*}\right)}{\left(x^{*}\right)}}$ and $B^{*}=\frac{\Omega_{x}^{*}}{\Phi\left(x^{*}\right)} \frac{\Phi\left(x^{*}\right)}{\Phi_{x}^{*}}-1$. If two economies are distinct, but share the same $\Omega(x)$, then $\Phi(x)$ must be different, which implies $\left\{B^{*}, \mu^{*}, q^{*}\right\}$ must be different as well.

(iii) Using the expressions derived above, if an economy has a lower $\Phi(x)$ then $B^{*}$ and $\mu^{*}$ are greater, while $q^{*}$ is smaller.

\section{B Monetary economies}

\section{B.1 Competitive Markets}

Assume the day-market is competitive. A consumer faces a day-budget constraint, $\tilde{p} x \leq m$, where $\tilde{p}$ is the - normalized - market price of good $x$. Using $\xi$ as the Lagrange multiplier associated with this constraint, the problem of a consumer can be written as

$$
V^{c}(m, b)=\max _{x} u(x)+W(0)+\frac{\alpha(m+b-\tilde{p} x)}{p(1-\tau)}+\xi(m-\tilde{p} x) .
$$

The first-order condition implies

$$
\xi=\frac{u_{x}}{\tilde{p}}-\frac{\alpha}{p(1-\tau)}
$$

The problem of a producer is

$$
V^{p}(m, b)=\max _{\kappa}-f(\kappa)+W(0)+\frac{\alpha(m+b+\tilde{p} \kappa)}{p(1-\tau)} .
$$

The first-order condition is

$$
-f_{\kappa}+\frac{\alpha \tilde{p}}{p(1-\tau)}=0
$$

The day market clearing condition is $\eta=(1-\eta) \tilde{p} \kappa$, which, given $\eta x=(1-\eta) \kappa$, implies $\tilde{p}=\frac{1}{x}$. Thus, the expression above and $(7)$, imply $\Phi(x) \equiv f_{\kappa} x$. From the envelope conditions we get $V_{m}^{c}=\frac{u_{x}}{\tilde{p}}$ and $V_{m}^{p}=\frac{\alpha}{p(1-\tau)}$. Thus, $\Omega(x) \equiv \eta x\left(u_{x}-f_{\kappa}\right)$. 


\section{B.2 Financial intermediation}

One important inefficiency in the economy described above is due to the inability of producers in the day to lend their idle cash balances. Thus, consider a monetary economy that resolves this financial friction by assuming the existence of a technology that record financial transactions, as suggested by Berentsen et al. (2007). Financial intermediation is conducted by perfectly competitive banks, which accept nominal deposits and make nominal loans. Banks are endowed with a technology that allows them to record financial histories at zero cost. However, trading histories cannot be recorded. Banks cannot issue their own notes, nor can they provide thirdparty verification for government bonds in transactions between agents. Thus, money is still used as the only medium of exchange in the day market. The added feature is that now, at the beginning of each period, sellers can deposit their money holdings at banks, and buyers can borrow money from banks. Deposits and loans mature at night. Perfect competition in the banking sector implies that the deposit and loan interest rates are equal. Let $i \geq 0$ be the bank nominal interest rate. Assume perfect enforcement and no borrowing constraints in financial markets.

A consumer in the day market enters the period with $m$ units of fiat money and $b$ units of government bonds. Being generally cash-constrained, he borrows $\ell$ units of fiat money from the bank with the obligation to repay $(1+i) \ell$ units of money at night. The consumer then uses $m+\ell$ to buy $x$ goods at price $\tilde{p}$. Thus, his starting nominal balances at night - net of loan obligations - are equal to $m+b-\tilde{p} x-i \ell$. Using $\xi$ as the Lagrange multiplier associated with the budget constraint, the problem of a consumer is

$$
V^{c}(m, b)=\max _{x, \ell} u(x)+W(0)+\frac{\alpha(m+b-\tilde{p} x-i \ell)}{p(1-\tau)}+\xi(m+\ell-\tilde{p} x) .
$$

The first-order conditions imply

$$
\begin{aligned}
\xi & =\frac{u_{x}}{\tilde{p}}-\frac{\alpha}{p(1-\tau)} \\
i & =\frac{u_{x} p(1-\tau)}{\alpha \tilde{p}}-1 .
\end{aligned}
$$

Note that $i=0$ if and only if $\xi=0$.

A producer has no use for cash and thus, deposits his money holdings at the bank. If he starts the period with $m$ units of money and $b$ units of government bonds, deposits $d$ units of money and sells $\kappa$ units of the day-good at price $\tilde{p}$, his starting nominal balances at nightincluding deposit claims - are $m+b+\tilde{p} \kappa+i d$. The problem of a producer can be written as

$$
V^{p}(m, b)=\max _{\kappa, d}-f(\kappa)+W(0)+\frac{\alpha(m+b+\tilde{p} \kappa+i d)}{p(1-\tau)}+\xi_{d}(m-d),
$$

where $\xi_{d}$ is the Lagrange multiplier associated with the constraint that states that an agent cannot deposit more than his fiat money holdings. The first-order conditions imply

$$
\begin{aligned}
f_{\kappa} & =\frac{\alpha \tilde{p}}{p(1-\tau)} \\
\xi_{d} & =\frac{\alpha i}{p(1-\tau)} .
\end{aligned}
$$

The second equation shows that producers deposit all their money holdings if $i>0$. Without loss of generality, assume that they also deposit all their money holdings when $i=0$.

The market clearing conditions are $\eta \ell=(1-\eta) d$ and $(1-\eta) \tilde{p} \kappa=\eta(1+\ell)$. The first equation states that the total amount of money borrowed from banks has to equal the total amount of 
money that was deposited at banks. The second equation states that the nominal value of total output sold by producers has to equal total money holdings - including loans - of buyers. Note that since producers deposit all their money holdings, $d=1$ and thus, $\ell=\frac{1-\eta}{\eta}$, which implies $(1-\eta) \tilde{p} \kappa=1$. Using the day-resource constraint, $\eta x=(1-\eta) \kappa$, we get $\tilde{p}=\frac{1}{\eta x}$. Thus, the equilibrium in the day market is characterized by

$$
\begin{aligned}
i & =\frac{u_{x}}{f_{\kappa}}-1 \\
\eta f_{\kappa} x & =\frac{\alpha}{p(1-\tau)} .
\end{aligned}
$$

Thus, $\Phi(x) \equiv \eta f_{\kappa} x$. From the envelope conditions we get $V_{m}=\eta u_{x} x$, which implies $\Omega(x) \equiv$ $\eta x\left(u_{x}-f_{\kappa}\right)$.

\section{B.3 Trading frictions}

Consider the economy without financial intermediation, but assume now that the day-good is traded in a decentralized market. I abstract from search frictions, i.e., the possibility that an agent does not meet someone with whom to trade in the day-market. ${ }^{12}$ Thus, let $\eta=\frac{1}{2}$ and assume all agents in the day are matched in consumer-producer pairs. In these bilateral meetings, consumers and producers bargain over the terms of trade: a quantity $x$ and a monetary transfer (normalized by the aggregate money stock) $\delta$. Here, we need to make the additional assumption $u(0)=0$ to ensure the trading surplus is positive. In terms of the bargaining problem, I follow the analysis in Aruoba et al. (2007) and adopt the proportional solution due to Kalai (1977). Below, I also consider the Nash (1950) bargaining solution and show why it is not suitable for policy analysis in this context.

Suppose the terms of trade agreed in a bilateral meeting are $\{x, \delta\}$. A consumer that starts the period with nominal holdings $\{m, b\}$ gets $u(x)+W(m-\delta+b)=u(x)+W(0)+\frac{\alpha(m+b-\delta)}{p(1-\tau)}$; similarly, a producer starting with the same nominal holdings gets $-f(x)+W(m+\delta+b)=$ $-f(x)+W(0)+\frac{\alpha(m+b+\delta)}{p(1-\tau)}$. If no agreement is reached, both agents get $W(m+b)=W(0)+\frac{\alpha(m+b)}{p(1-\tau)}$.

Given consumer's bargaining weight $\theta \in(0,1]$ and consumer's money holdings $m$, the proportional solution is given by

$$
\{x, \delta\}=\underset{x, \delta \leq m}{\operatorname{argmax}} u(x)-\frac{\alpha \delta}{p(1-\tau)}
$$

subject to $(1-\theta)\left(u(x)-\frac{\alpha \delta}{p(1-\tau)}\right)=\theta\left(-f(x)+\frac{\alpha \delta}{p(1-\tau)}\right)$. Following standard arguments, we can show that in a monetary equilibrium $\delta=m=1$ and

$$
\Phi(x)=\frac{\alpha}{p(1-\tau)},
$$

where $\Phi(x) \equiv(1-\theta) u(x)+\theta f(x)$.

The terms of trade are not affected by the money holdings of a producer. Thus, $V_{m}^{p}=W_{z}=$ $\frac{\alpha}{p(1-\tau)}$, i.e., $V_{m}^{p}=\Phi(x)$. On the other hand, $V_{m}^{c}=u_{x} \frac{\partial x}{\partial m}+\frac{\alpha}{p(1-\tau)}\left(1-\frac{\partial \delta}{\partial m}\right)$. If a consumer brings one more unit of money to the match, then $x$ increases by $\frac{\alpha}{p(1-\tau) \Phi_{x}}$ and $\delta$ goes up by 1 . Thus, we get $V_{m}^{c}=\frac{\Phi(x) u_{x}}{\Phi_{x}}$, and so $V_{m}=\frac{\Phi(x)\left(u_{x}+\Phi_{x}\right)}{2 \Phi_{x}}$ and $\Omega(x) \equiv \frac{\theta \Phi(x)\left(u_{x}-f_{x}\right)}{2 \Phi_{x}}$.

\footnotetext{
${ }^{12}$ Note that this is a standard assumption when these type of models are calibrated.
} 


\section{B.4 Nash bargaining}

Consider the environment with trading frictions, but use instead the Nash (1950) solution to the bargaining problem:

$$
\{x, \delta\}=\underset{x, \delta \leq m}{\operatorname{argmax}}\left(u(x)-\frac{\alpha \delta}{p(1-\tau)}\right)^{\theta}\left(-f(x)+\frac{\alpha \delta}{p(1-\tau)}\right)^{1-\theta} .
$$

A monetary equilibrium under the Nash solution looks identical to the proportional solution derived above, except for the expression for $\Phi(x)$. With Nash, we get $\Phi(x) \equiv(1-\Theta(x)) u(x)+$ $\Theta(x) f(x)$, where $\Theta(x)=\frac{\theta u_{x}}{\theta u_{x}+(1-\theta) f_{x}}$.

One feature of the Nash solution that sets it apart from all the other cases considered in this paper, is that the function $\Omega(x)$ crosses zero at some point below $\hat{x}$ and hence, we cannot guarantee that the non-negativity constraint, $\Omega(x) \geq 0$, will not bind. In other words, it may be possible that the equilibrium under the Nash solution features a zero nominal interest rate for all levels of debt. When applying the calibration with the proportional solution (see Table 3 ) to the Nash bargaining case, we obtain $\Omega(\mathcal{X}(B))=0$ for all $B \in \Gamma$. Increasing $\theta$ to 0.999 resolves this issue but the steady state statistics are off target. When solving for parameter values that calibrate the economy with the Nash bargaining solution to the U.S. economy, there does not seem to be a solution. See Aruoba et al. (2007) for further analysis of the differences between the Nash and Kalai bargaining solutions in the Lagos-Wright framework, for the case with exogenous government policy.

\section{Parameter-elasticities for Table 5}

\begin{tabular}{|c|c|c|c|c|c|c|c|c|c|c|c|c|c|c|c|c|c|}
\hline & \multicolumn{6}{|c|}{ Competitive Markets } & \multicolumn{6}{|c|}{ Financial Intermediation } & \multicolumn{5}{|c|}{ Trading Frictions } \\
\hline & $\Delta \alpha$ & $\Delta \phi$ & $\Delta \eta$ & $\Delta \rho$ & $\Delta \sigma$ & $\Delta \psi$ & $\Delta \alpha$ & $\Delta \phi$ & $\Delta \eta$ & $\Delta \rho$ & $\Delta \sigma$ & $\Delta \psi$ & $\Delta \alpha$ & $\Delta \phi$ & $\Delta \rho$ & $\Delta \sigma$ & $\Delta \psi$ \\
\hline$\frac{B^{*}\left(1+\mu^{*}\right)}{Y^{*}}$ & -0.55 & 0.69 & 1.82 & -0.38 & 2.22 & -0.13 & -0.43 & 0.47 & 0.80 & -0.22 & 2.69 & -0.21 & -0.50 & -0.72 & -0.32 & 13.07 & -0.19 \\
\hline$\pi^{*}$ & -0.96 & 0.00 & 1.74 & -1.51 & 2.04 & 1.45 & -0.90 & 0.00 & 0.00 & -1.39 & 1.89 & 1.31 & -0.91 & -0.85 & -1.48 & 7.70 & 1.38 \\
\hline$\tau^{*}$ & -0.55 & 0.00 & 0.00 & -0.09 & 0.00 & 0.73 & -0.54 & 0.00 & 0.00 & -0.05 & 0.00 & 0.71 & -0.54 & 0.00 & -0.11 & 0.00 & 0.73 \\
\hline$\frac{p^{*} \tau^{*} n^{*}}{Y^{*}}$ & -0.55 & -0.06 & 0.00 & -0.15 & 0.00 & 0.83 & -0.51 & -0.10 & -0.16 & -0.10 & -0.10 & 0.85 & -0.54 & -0.02 & -0.17 & -0.15 & 0.83 \\
\hline$\frac{p^{*} g^{*}}{Y^{*}}$ & -0.51 & -0.06 & 0.00 & -0.07 & 0.00 & 0.77 & -0.47 & -0.10 & -0.16 & -0.03 & -0.10 & 0.79 & -0.50 & -0.02 & -0.10 & -0.15 & 0.77 \\
\hline
\end{tabular}

\section{Numerical approximation of stochastic economies}

The monetary economies with aggregate uncertainty are solved globally using a projection method with the following algorithm:

(i) Define a grid of $N_{\Gamma}$ points over $\Gamma$. The stochastic state space $S$ is discretized in $N_{S}$ states, using the method described in Tauchen (1986). ${ }^{13}$ Create the indexed functions $\mathcal{B}^{i}(B)$, $\mathcal{X}^{i}(B), \mathcal{C}^{i}(B)$, and $\mathcal{G}^{i}(B)$, for $i=\left\{1, \ldots, N_{S}\right\}$, and set an initial guess.

(ii) Construct the following system of equations: for every point in the debt and exogenous state grids, evaluate equations $(21)-(24)$. Since $(22)$ contains $\mathcal{X}^{j}\left(\mathcal{B}^{i}(B)\right)$ (and its derivative) and $\mathcal{G}^{j}\left(\mathcal{B}^{i}(B)\right)$, use cubic splines to interpolate between debt grid points and calculate the derivatives of policy functions.

\footnotetext{
${ }^{13}$ See Flodén (2008) for a recent comparison with alternative methods.
} 
(iii) Use a non-linear equations solver to solve the system in (ii). There are $N_{\Gamma} \times N_{S} \times 4$ equations. The unknowns are the values of the policy function at the grid points. In each step of the solver, the associated cubic splines need to be updated so that the interpolated evaluations of future choices are consistent with each new guess.

We could alternatively simplify step (iii) by using value function iteration: simply solve the maximization problem of the government at every grid point. Update the policy and value functions and iterate until convergence is achieved. This method is simpler to implement, but less precise. However, relative to the algorithm described above, it serves a dual purpose: first, it can be used to obtain a good initial guess for policy functions; and second, it provides a method to verify the numerical approximation found using the first-order conditions, as described above.

Each exogenous stochastic process is approximated by 7 discrete states, which implies $N_{S}=$ 49. For debt, I set $N_{B}=10$ and let $\Gamma=[-1.0,3.5]$. There are a total of 196 functions to solve. Given that the debt grid has 10 points, we have to solve a system of 1,960 equations. To measure the precision of the solution, I create a debt grid of 1,000 points for $\Gamma$, evaluate (21) - (24) for all these debt points and all $s \in S$, and sum the squared residuals. For the case with competitive markets, the sum of squared residuals for each equation are, respectively: $2 e^{-11}, 2 e^{-14}, 3 e^{-12}$ and $3 e^{-13}$. The other two cases feature similar degrees of precision.

Finally, we need to construct measures of real GDP and the inflation rate. In the model, real GDP is measured using the non-stochastic steady state as the base period for prices. Thus, let $y_{t}=\ln \left(\tilde{p}^{*} x_{t}+p^{*}\left(c_{t}+g_{t}\right)\right)$ be the measure of log real GDP in the artificial economy and let $d y_{t}$ be log real GDP in period $t$ minus its sample average. To calculate the inflation rate, define the aggregate (normalized) price level $P$ as the weighted average of prices in the day and night markets. I.e., for any period $t$, let $P_{t} \equiv s_{D} \tilde{p}_{t}+s_{N} p_{t}$, where $s_{D}$ and $s_{N}$ are the expenditure shares for the day and night markets, respectively. Expenditure shares are constructed using the non-stochastic steady state statistics as the base period: $s_{D} \equiv \frac{\tilde{p}^{*} x^{*}}{Y^{*}}$ and $s_{N} \equiv \frac{p^{*}\left(c^{*}+g^{*}\right)}{Y^{*}}$. The inflation rate is defined as: $\pi_{t} \equiv \frac{P_{t}\left(1+\mu_{t-1}\right)}{P_{t}-1}-1$. 
Figure 1: Impulse response functions

Response to one Cholesky s.d. expenditure innovation

Deficit / GDP
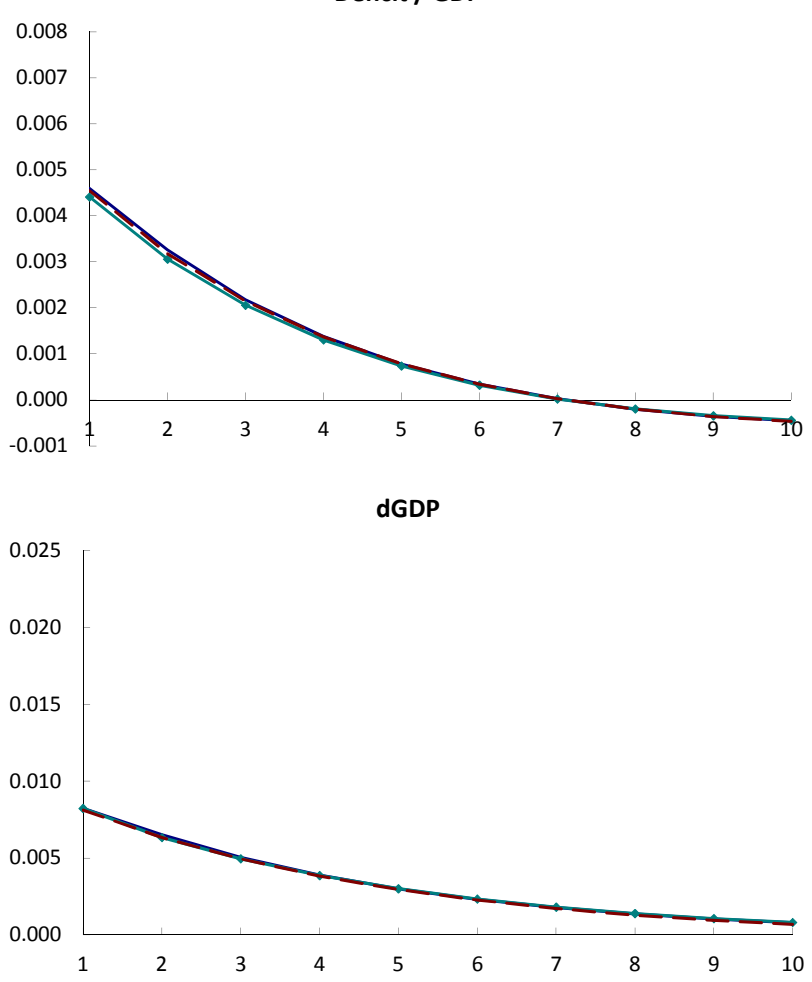

Money Growth Rate
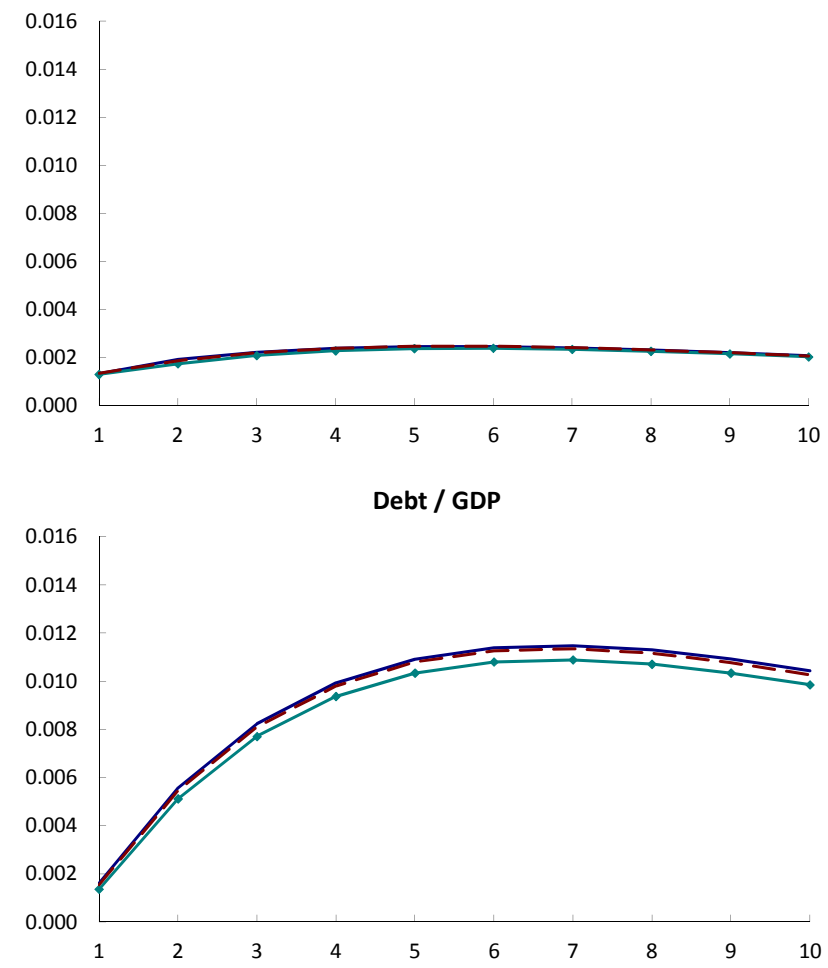

Response to one Cholesky s.d. productivity innovation

Deficit / GDP

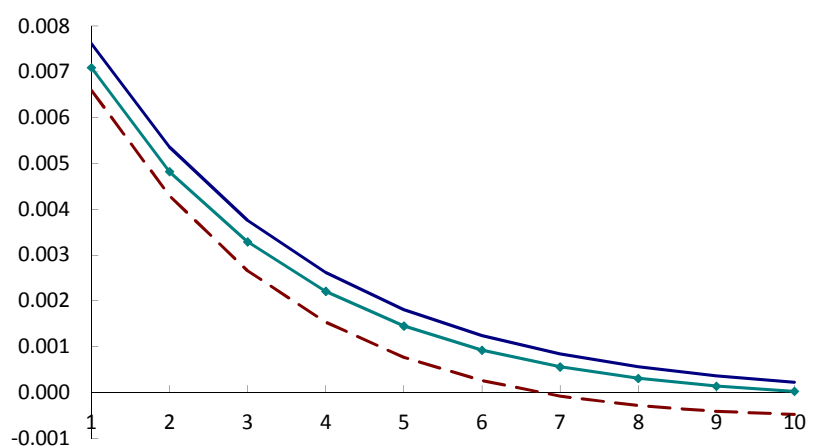

dGDP

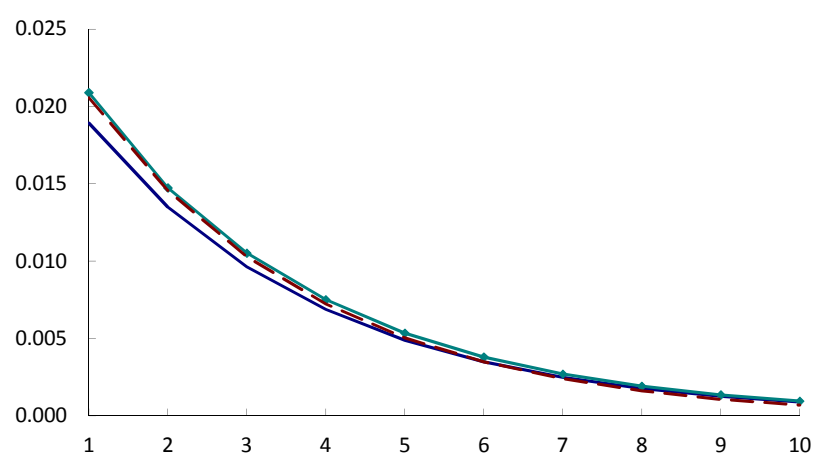

Money Growth Rate

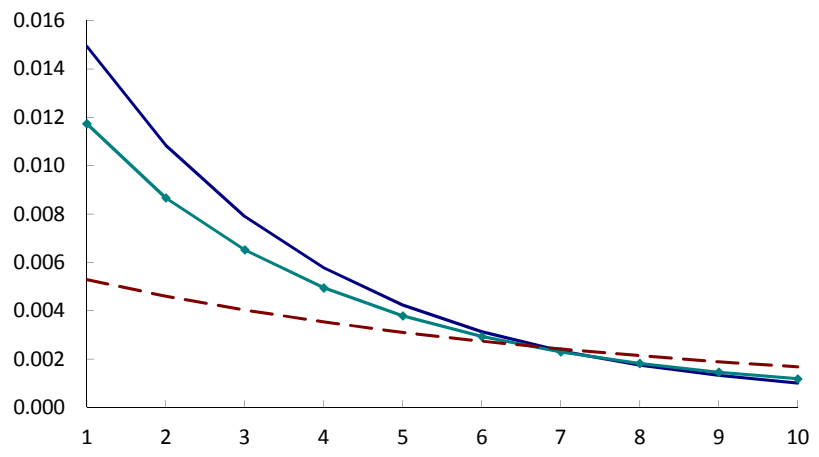

Debt / GDP

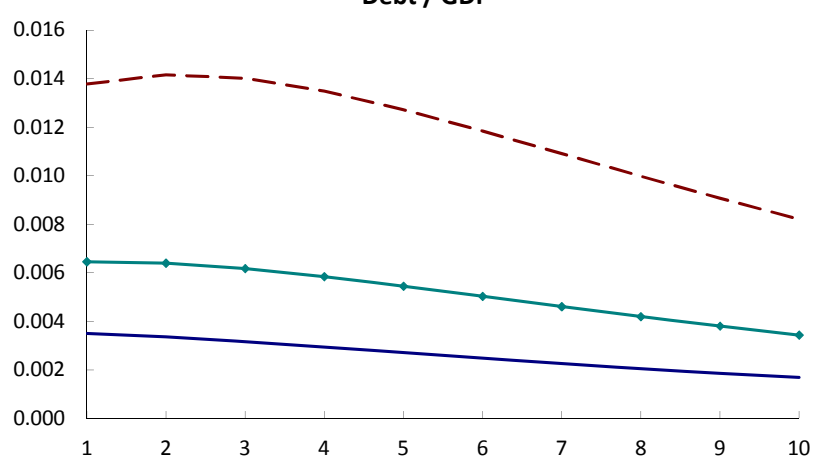

Note. Competitive Markets: solid lines; Financial Intermediation: solid lines with diamonds markers; Trading Frictions: dashed lines. 
Figure 2: k-variance ratios of policy variables
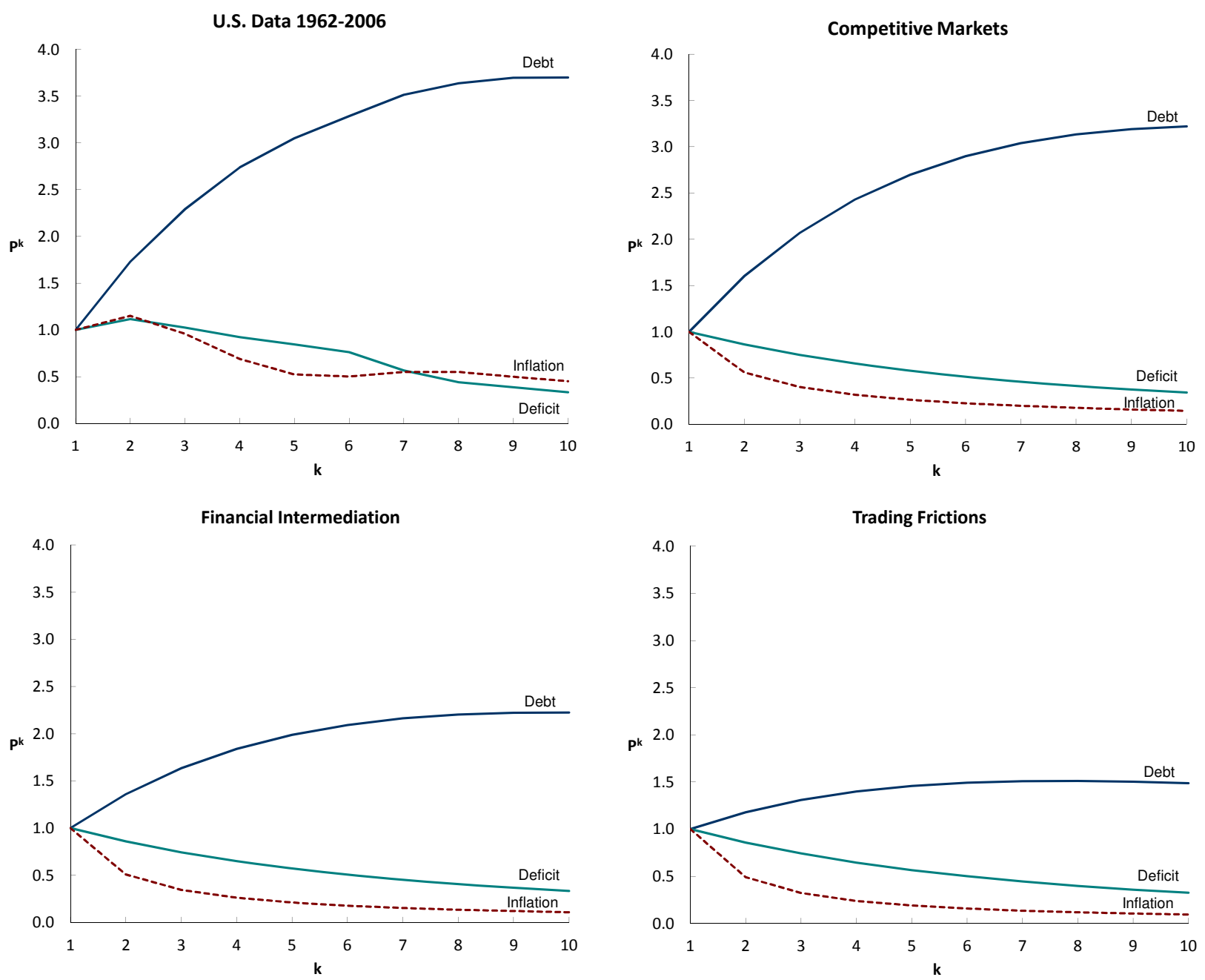
Figure 3: Money demand
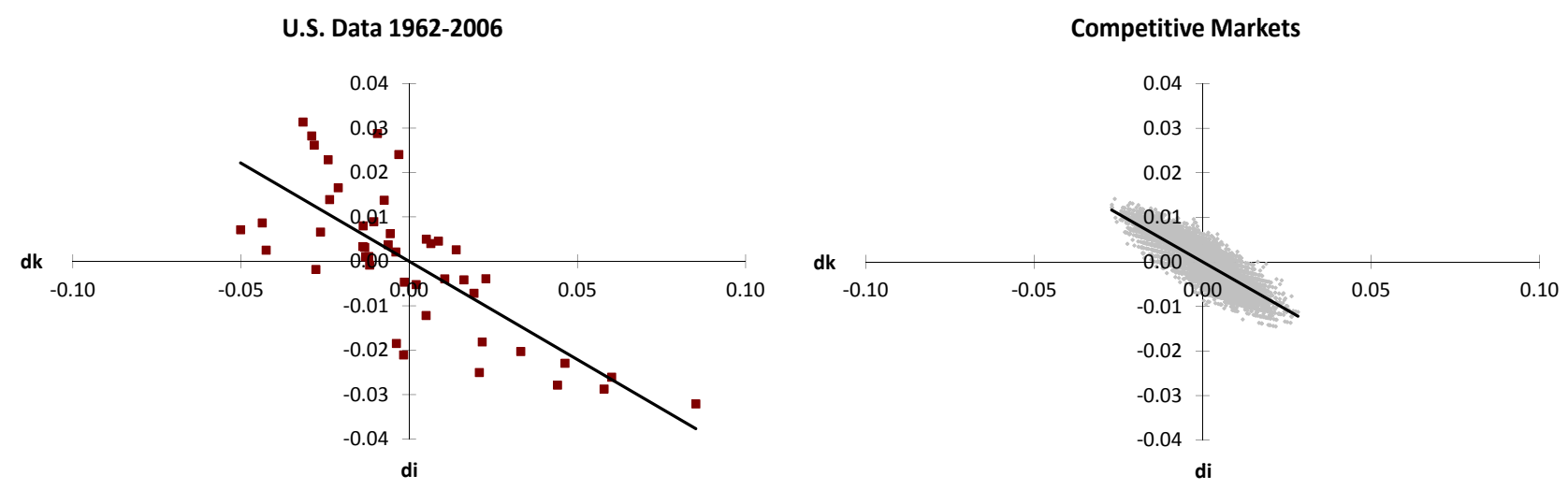

Financial Intermediation
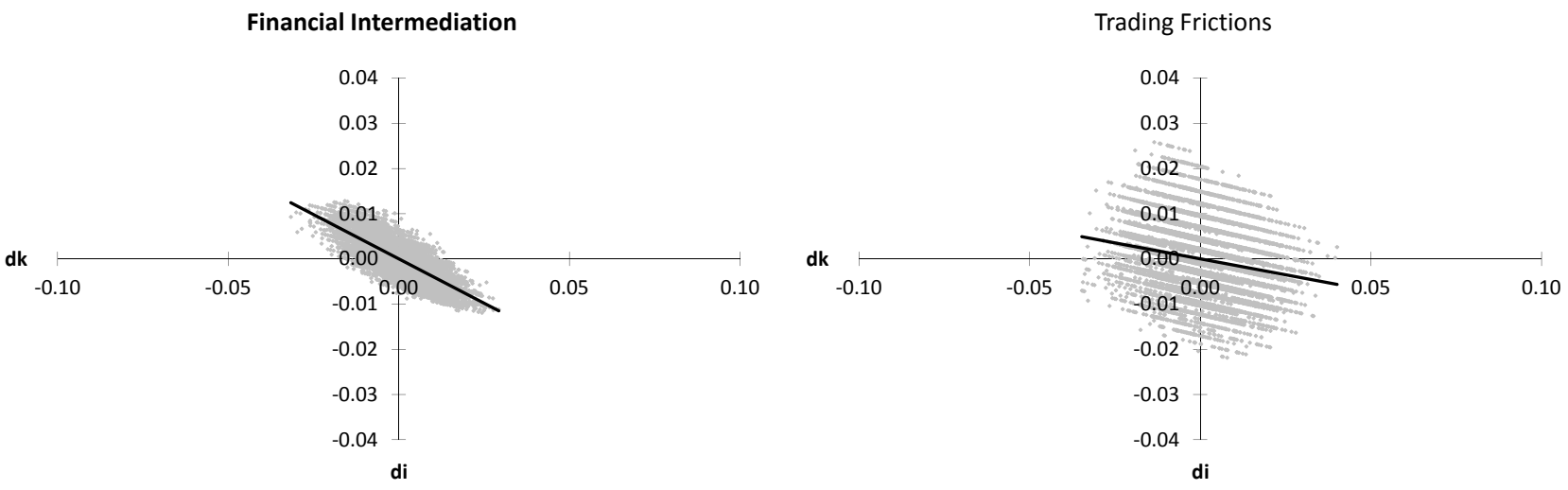
Figure 4: Phillips curve

U.S. Data 1962-2006

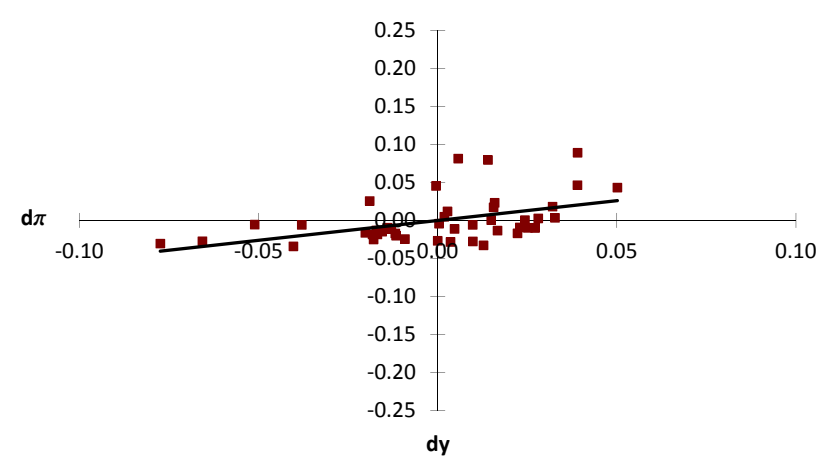

Financial Intermediation

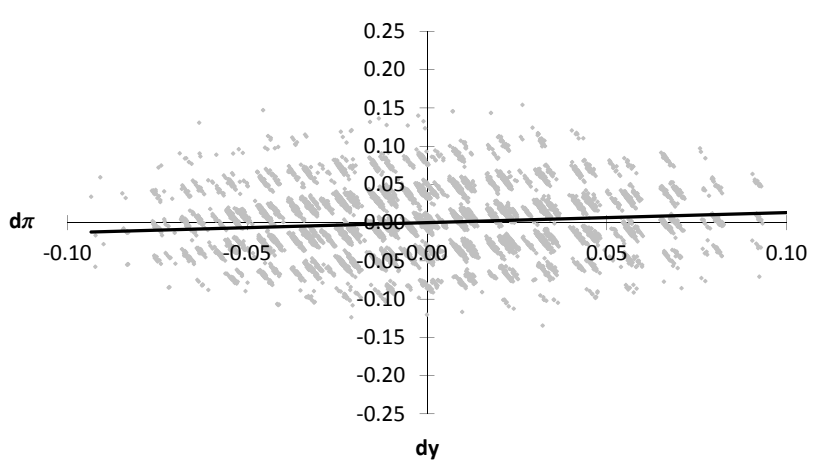

Competitive Markets

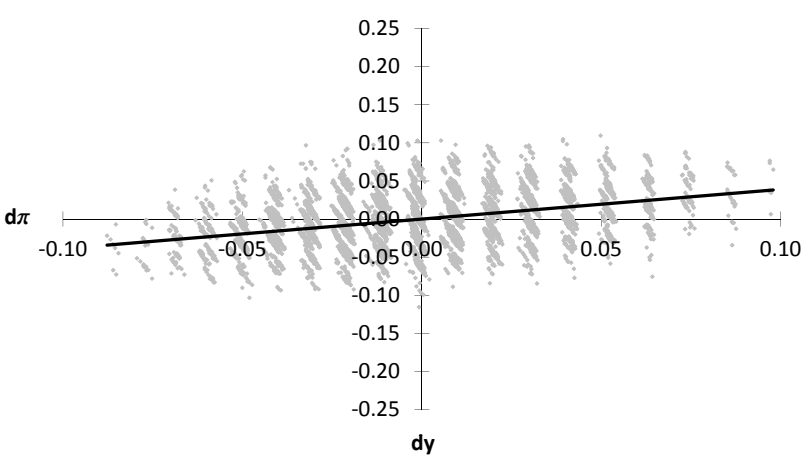

Trading Frictions

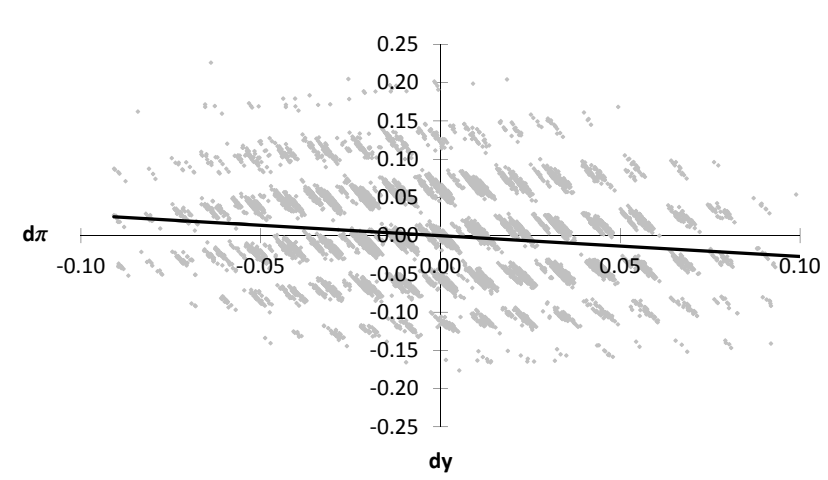

